\title{
Herba Cistanches: Anti-aging
}

\author{
Ningqun Wang1, \#, Shaozhen $\mathrm{Ji}^{2}$,\#, Hao Zhang ${ }^{3}$, Shanshan $\mathrm{Mei}^{2}$, Lumin Qiao4, Xianglan Jin ${ }^{5}$ * \\ ${ }^{1}$ Department of Traditional Chinese Medicine, Xuanwu Hospital, Capital Medical University, Beijing 100053, \\ China. \\ ${ }^{2}$ Department of Neurology, Xuanwu Hospital, Capital Medical University, Beijing 100053, China. \\ ${ }^{3}$ Department of Radiology, Dongfang Hospital of Beijing University of Chinese Medicine, Beijing 100078, China \\ ${ }^{4}$ Department of Emergency, Traditional Chinese Medicine Hospital of Yinchuan, Ningxia Hui Nationality \\ Autonomous Region 750001, China. \\ ${ }^{5}$ Department of Neurology, Dongfang Hospital of Beijing University of Chinese Medicine, Beijing 100078, China.
}

[Received December 7, 2016; Revised July 2, 2017; Accepted July 20, 2017]

\begin{abstract}
The Cistanche species ("Rou Cong Rong” in Chinese) is an endangered wild species growing in arid or semi-arid areas. The dried fleshy stem of Cistanches has been used as a tonic in China for many years. Modern pharmacological studies have since demonstrated that Herba Cistanches possesses broad medicinal functions, especially for use in anti-senescence, anti-oxidation, neuroprotection, anti-inflammation, hepatoprotection, immunomodulation, anti-neoplastic, anti-osteoporosis and the promotion of bone formation. This review summarizes the up-to-date and comprehensive information on Herba Cistanches covering the aspects of the botany, traditional uses, phytochemistry and pharmacology, to lay ground for fully elucidating the potential mechanisms of Herba Cistanches' anti-aging effect and promote its clinical application as an antiaging herbal medicine.
\end{abstract}

Key words: Herba Cistanches, anti-senescence, anti-oxidation, neuroprotection

\section{Introduction}

Cistanche Hoffmg. Et Link is a holoparasitic desert genus belonging to the Orobanchaceae family and has 22 species throughout the world. The Cistanche species include the perennial parasite herbs, which commonly attach itself to the roots of sand-fixing plants, such as Haloxylon ammodendron, $H$. persicum, Kalidium foliatum, and Tamarix plants [1]. Generally, species of the genus of Cistanche are found in arid lands and warm deserts in the northern hemisphere, such as the provinces of Xinjiang, Inner Mongolia, Gansu, Qinghai, and the Ningxia Hui Nationality Autonomous Region in China in addition to similar regions of countries such as Iran, India, and Mongolia [2].
According to the Taxonomical Index of Chinese Higher Plants, there are six Cistanche species in China [3]. However, it was confirmed that only four species and one variation of cistanche exist in China, including Cistanche deserticola Y. C. Ma, Cistanche tubulosa (Schenk) R. Wight, Cistanche salsa (C. A. Mey.) G. Beck, Cistanche salsa var. albiflora P.F. Tuet Z.C. Lou and C. sinensis G. Beck Herba [4]. Among the Cistanche species, only C. deserticola has been reordered in the Chinese Pharmacopoeia (2000 edition) [5], and C. tubulosa was added to the 2005 Chinese Pharmacopoeia as an alternative, for its similar chemical constituents, pharmacological activities and its relatively affluent resource compared to C. deserticola [6].

*Correspondence should be addressed to: Dr. Xianglan Jin, Department of Neurosurgery, Dongfang Hospital of Beijing University of Chinese Medicine, Beijing 100078, China. Email: jinxianglan666@126.com. \#These authors contributed equally to this study.

Copyright: () 2017 Wang N et al. This is an open-access article distributed under the terms of the Creative Commons Attribution License, which permits unrestricted use, distribution, and reproduction in any medium, provided the original author and source are credited. 
As a tonic, Herba Cistanches ("Rou Cong Rong" in Chinese) has been used for chronic renal disease, impotence, female infertility, morbid leucorrhea, profuse menorrhagia and senile constipation [7]. Because of its efficacy and moderate tonic character, Herba Cistanches is widely accepted and has earned the honor of "Ginseng in the deserts".

Aging, the complex irreversible process in one's life, is the decline in physiological body function and degradation of integrated performance. As the major risk factor for several life-threatening diseases, aging is driven by diverse molecular pathways and biochemical events that are influenced by the interplay of environmental and genetic factors [8]. Two hundred and ninety-eight genes have been collected from published works associated with aging [9]. As a biomarker of chronological aging, telomere length is linked to various aging associated diseases [10].

Table 1. The functions and mechanisms of Herba Cistanches extracts with anti-aging or anti-aging related effects.

\begin{tabular}{|c|c|c|c|}
\hline Extracts & Function & Mechanisms & Refs. \\
\hline \multirow[t]{3}{*}{$\begin{array}{l}\text { Ethanol extract of } \\
\text { Herba Cistanches }\end{array}$} & Lifespan elongation & $\begin{array}{l}\text { antagonize immunosenescence, exhibit analgesic and anti- } \\
\text { inflammatory properties, improve blood circulation, increase the } \\
\text { weights of the seminal vesicle, prostate gland and testes, modulate } \\
\text { serum hormone level, induct testicular steroidogenic enzymes, delay } \\
\text { accumulation of lactic acid, improve energy storage }\end{array}$ & {$[23-31,36]$} \\
\hline & Cardioprotection & $\begin{array}{l}\text { reduce oxidative stress, inhibit apoptotic pathways, } \\
\text { enhance mitochondrial ATP-GC and confer cardioprotection against } \\
\text { ischemia/reperfusion (I/R) injury }\end{array}$ & {$[32,34]$} \\
\hline & Neuroprotection & $\begin{array}{l}\text { increase neuronal cell differentiation, neurite length, and synapse } \\
\text { formation, upregulate NGF }\end{array}$ & [33] \\
\hline \multirow{7}{*}{$\begin{array}{l}\text { Aqueous extract of } \\
\text { Herba Cistanches }\end{array}$} & Lifespan elongation & inhibit cell apoptosis & [38] \\
\hline & Antioxidant activity & $\begin{array}{l}\text { inhibit activation of macrophage cells and nitric oxide production, } \\
\text { scavenge free radicals }\end{array}$ & {$[37,39]$} \\
\hline & Hepatoprotection & inhibit lipid peroxidation in liver microsomes & [39] \\
\hline & Anti-neoplastic effect & $\begin{array}{l}\text { upregulate nitric oxide synthase II expression, stimulate } \\
\text { phagocytosis }\end{array}$ & [40] \\
\hline & $\begin{array}{l}\text { Memory and learning } \\
\text { enhancement }\end{array}$ & block A $\beta 1-42$ amyloid deposition & [41] \\
\hline & $\begin{array}{l}\text { Anti-osteoporosis } \\
\text { effect }\end{array}$ & $\begin{array}{l}\text { regulate bone metabolism related genes e.g., Smad1, Smad5, TGF- } \\
\beta 1 \text { and TIEG1 }\end{array}$ & [42-44] \\
\hline & Aphrodisiac effect & $\begin{array}{l}\text { alleviate spermatogenetic cell degeneration, modulate serum sex } \\
\text { hormones levels }\end{array}$ & [45-46] \\
\hline \multirow[t]{3}{*}{$\begin{array}{l}\text { Methanol extract } \\
\text { of Herba } \\
\text { Cistanches }\end{array}$} & Cardioprotection & $\begin{array}{l}\text { enhance mitochondrial glutathione status, decrease mitochondrial } \\
\mathrm{Ca}^{2+} \text { level, decrease myocardial ATP depletion, mitochondrial } \\
\text { membrane potential and respiration rate }\end{array}$ & [47-48] \\
\hline & Vasorelaxant activity & inhibit contractions induced by noradrenaline & [49] \\
\hline & Hepatoprotection & $\begin{array}{l}\text { inhibit D-GalN-induced death of hepatocytes, reduce TNF- } \alpha \text {-induced } \\
\text { cytotoxicity in L929 cells }\end{array}$ & [49] \\
\hline
\end{tabular}

There are several outstanding theories including mitochondrial mutation, oxidative damage, carbonyl toxification and free radical theory associated with phenomenon of aging $[11,12]$. Excessive reactive oxygen species (ROS) produced during metabolism could easily lead to damage cell membranes, nucleic acids, proteins, enzymes and other biological macromolecules through peroxidation. ROS mediated modifications of delayed- rectifier and $\mathrm{Ca}^{2+}$ activated $\mathrm{K}^{+}$channels could be linked to altered electrophysiology of neurons with clear implications in brain aging [13]. Lipid peroxidation and large amounts of harmful metabolites such as malondialdehyde (MDA) on the cell membrane, abnormality of DNA mutation or replication, together with decline of enzymes activity, consequently lead to serious damage on cell function and eventually results in 
senility and even death [14]. Oxidative stress has been the main cause in the etiology of many diseases, which includes Parkinson's disease (PD), Alzheimer's disease (AD), Huntington's disease and hepatic fibrosis.

Besides genes and oxidative stress, structural and functional defects in the immune system are closely related to aging. Immunological dysfunction with aging contributes to the increased incidence of different chronic diseases with an inflammatory component [15]. The inflammatory state is characterized by an inflammatory origin of aging given by the activation of cellular systems responsible for gene promotion and suppression such as the nuclear factor kappa B (NF-kB), sirtuins, forkhead box $\mathrm{O}$ and KLOTHO, which are directly or indirectly involved in cellular mechanisms of resistance to oxidative stress, apoptosis and nucleic acids repair [16].

Degenerative loss of tissue or cellular functions in the brain with a manifestation of declining logical thinking, memory and spatial abilities, is also one of the main characteristics of aging [17, 18].

Although Herba Cistanches has been used as an elixir for thousands of years, scientific research on Cistanche plants started in the 1980s. Chemical analysis indicated that various compounds, including essential oils, phenylethanoid glycosides (PhGs), iridoids, lignans, alditols, oligosaccharides and polysaccharides are the main constitutes of Cistanche plants [19]. Pharmacological research showed that extracts from Cistanche plants possess a wide spectrum of activities, such as increasing the ability to learn and memorize, treating $\mathrm{AD}$, enhancing immunity, prolonging lifespan, as well as anti-aging and anti-fatigue effects [20-23]. This review aims to lay the ground for fully elucidating the potential mechanisms of Herba Cistanches' anti-aging effect to promote its clinical application as an anti-aging herbal medicine.

\section{Anti-aging and anti-aging related effects of Herba Cistanches extractions}

Till today, the chemical constituents of Herba Cistanches include volatile compounds and more than a hundred isolated non-volatile compounds, containing $\mathrm{PhGs,}$ iridoids, lignans, alditols, oligosaccharides and polysaccharides [19]. Herba Cistanches is traditionally water-extracted, and recently methanol and ethanol extractions are found to be satisfactory. The extractions of Herba Cistanches with direct lifespan elongation effects or potential anti-aging properties mainly includes the ethanolic extract of aqueous extract and methanol extract. Their functions and mechanisms are found in Table 1.

\subsection{Ethanol extract of Herba Cistanches}

Ethanol extract of Cistanche tubulosa possesses significant effects in extending lifespan, which is achieved by antagonizing immunosenescence [23]. It has exhibited powerful analgesic and anti-inflammatory properties [24] and has been shown to improve blood circulation by lowering blood cholesterol levels [25]. It also could promote hair growth and relieve dandruff and scalp inflammation [26, 27]. Ethanol extract of Cistanche deserticola could increase the weights of the seminal vesicle, prostate gland and testes of castrated young rats $[28,29]$. It facilitated the penis erectile response and modulated the serum hormone level to some extent [30], and also increased sex hormone levels mediated by the induction of testicular steroidogenic enzymes [31]. Herba Cistanches alcohol extract has cardioprotective and neuroprotective effects [32-34] by significantly enhancing learning and memory, and increasing neuronal cell differentiation, neurite length, and synapse formation in the mouse hippocampus [33], and reducing the oxidative stress in the reperfused myocardium, inhibiting apoptotic pathways [34]. In addition, Herba Cistanches alcohol extract possesses a sedative effect [35] and enhanced the swimming capacity of mice by decreasing muscle damage, delaying the accumulation of lactic acid and improving energy storage [36].

\subsection{Aqueous extract of Herba Cistanches}

Aqueous extract of Herba Cistanches could regulate immunity [28, 29, 37], inhibit cell apoptosis [38] and scavenge free radicals [39]. It has an anti-inflammatory effect $[37,40]$ and could inhibit nitric oxide (NO) production from activated RAW 264.7 macrophages [37]. Aqueous extracts of Cistanche tubulosa reduced inflammatory hyperplastic polyps and helicobacter infection in mice [40] and ameliorated the cognitive dysfunction caused by $A \beta$ 1-42 via blocking amyloid deposition, reversing cholinergic and hippocampal dopaminergic neuronal function [41]. The water fraction of Cistanche deserticola extract could prolong the hexobarbital-induced sleeping time and reduce spontaneous motor activity [35]. Herba Cistanches aqueous extract exerts its protective effect against ovariectomized-induced bone degeneration and osteoporosis partly by regulating a few of the bone metabolism related genes e.g., Smad1, Smad5, transforming growth factor (TGF)- $\beta 1$ and TGF- $\beta$ inducible early gene 1 (TIEG1) [42-44]. It also alleviated the spermatogenetic cell degeneration induced by hydroxyurea [45] or Leigongteng (Radix et Rhizoma Tripterygii) [46] and modulated serum sex hormones levels to some extent [45]. 
A

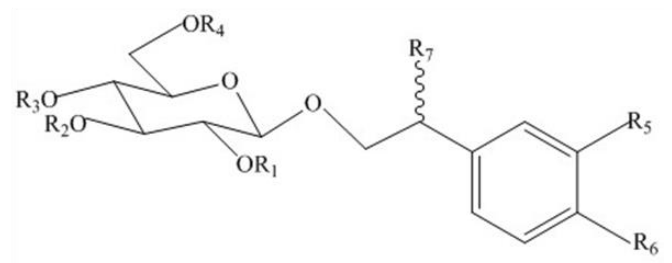

B

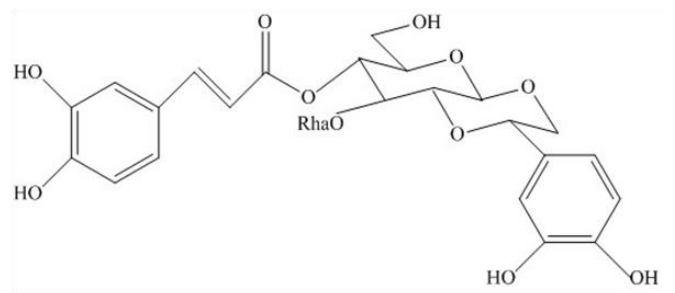

C

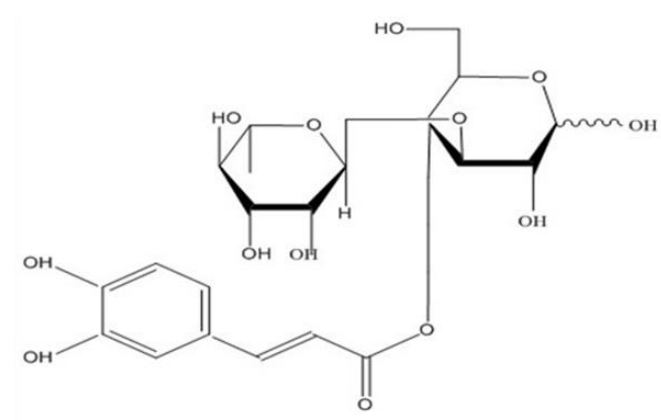

Figure 1. The chemical structures of PhGs. (A) Chemical structure of compounds 1-26 in PhGs. (B) Chemical structure of compound 27 (Crenatoside) in PhGs. (C) Chemical structure of compound 28 (Cistanoside F) in PhGs.

\subsection{Methanol extract of Herba Cistanches}

One study has shown that the methanol extract of Herba Cistanches protected against myocardial ischemia/ reperfusion (I/R) injury in rats through enhancing mitochondrial glutathione status, decreasing mitochondrial $\mathrm{Ca}^{2+}$ level, and increasing mitochondrial membrane potential and respiration rate in rat hearts [47]. The methanolic extract from the dried stems of Cistanche tubulosa (Schrenk) R. Wight containing echinacoside and acteoside was found to show vasorelaxant activity with an inhibitory effect on contractions induced by noradrenaline in isolated rat aortic strips [48]. In addition, the methanolic extract from fresh stems of Cistanche tubulosa (Orobanchaceae) was found to have hepatoprotective effects against D-galactosamine (DGalN)/ lipopolysaccharide (LPS)-induced liver injury in mice [49].

\section{Anti-aging and anti-aging related effects of PhGs}

Pharmacological studies have shown that PhGs were the major active components of Cistanche species. PhGs have various functions, such as anti-oxidation, neuroprotection, enhancing immune and sexual function, hepatoprotection, anti-radiation, etc. PhGs were usually regarded as markers for quality evaluation of crude drugs or their corresponding formulations. To date, PhGs have been well studied and $28 \mathrm{PhG}$ compounds have been isolated from Herba Cistanches (Table 2) (Fig. 1-3)

The empirical structural features of PhGs have been summarized. (1) The sugar moiety of glucose and rhamnose is connected by a Glc $(\mathbf{3} \rightarrow \mathbf{1})$ Rha linkage for disaccharide glycosides; the glucose commonly links directly to an aglycone, and acoumaroyl or caffeoyl is usually located at the $\mathrm{C} 4$ or C6 position. (2) For becoming trisaccharide glycosides, there is an additional glucose or rhamnose at the C6 position of the inside glucose [2].

Echinacoside and acteoside, which are two major compounds of PhGs with significant pharmacological activities, can be used as quality control markers for C. deserticola and C. tubulosa. According to the Chinese Pharmacopoeia, at least $0.3 \%$ of the total contents of echinacoside and acteoside for medical application should be determined from the dried stem of $\mathrm{C}$. deserticola by the high-performance liquid chromatography (HPLC) method [5].

PhGs with direct lifespan elongation effects or potential anti-aging properties mainly include the echinacoside, acteoside, isoacteoside and tubuloside which are known as the most important components of PhGs.

\subsection{Echinacoside}

Echinacoside is extracted from Cistanche tubulosa (Schrenk) R. Wight or Cistanche deserticola Y.C. Ma stems, especially in Cistanche tubulosa (Schrenk) R. Wight [56]. Its anti-aging effect has been shown in mice and cells, and it also has several anti-aging related effects, which supports its clinical application as an anti-aging drug. Its function and mechanisms are found in Table 3.

\subsubsection{Lifespan extension by echinacoside}

Echinacoside could protect cells against aging through its anti-oxidant effect. It also induced cell cycle arrest and apoptosis in SW480 cancer cells via induction of oxidative DNA damage $[57,58]$. The lifespan of wildtype worms could be extended in the presence of echinacoside. Echinacoside modulated the nuclear localization and transcriptional activities of daf-16, which fine-tuned the expression of daf-16 target genes to promote longevity and increase stress response in $\mathrm{C}$. elegans [59]. Progressive mitochondrial dysfunction is considered a hallmark of aging [60, 61]. It is generally believed that premature senescence and aging caused by ROS through oxidative metabolism cause accumulation 
of mtDNA damage and mutations leading to the loss of fidelity in newly synthesized proteins, which ultimately impacts mitochondria physiology $[62,63]$. The use of echinacoside in 1-methyl-4-phenylpyridinium ions $\left(\mathrm{MPP}^{+}\right.$)-exposed SH-SY5Y cells has been shown to selectively reverse mitochondrial function and cell apoptosis by preventing the decrease in membrane potential of fragmented mitochondria [64]. In addition, echinacoside prevented a $\mathrm{H}_{2} \mathrm{O}_{2}$-induced increase of the $\mathrm{Bax} / \mathrm{Bcl}-2$ ratio by down-regulating $\mathrm{Bax}$ protein expression and upregulating Bcl-2 protein expression [65].

Table 2. Phenylethanoid glycosides from Herba Cistanche.

\begin{tabular}{|c|c|c|c|c|c|c|c|c|c|}
\hline Active ingredient & $\mathbf{R}_{1}^{a}$ & $\mathbf{R}_{2}{ }^{\mathbf{a}}$ & $\mathbf{R}_{3}{ }^{\mathbf{a}}$ & $\mathbf{R}_{4}{ }^{a}$ & $\mathbf{R}_{5}{ }^{\mathrm{a}}$ & $\mathbf{R}_{6}{ }^{a}$ & $\mathbf{R}_{7}^{\mathrm{a}}$ & Species $^{b}$ & Refs. \\
\hline 2'-Acetylacteoside (1) & Ac & Rha & $\mathrm{Cf}$ & $\mathrm{H}$ & $\mathrm{OH}$ & $\mathrm{OH}$ & $\mathrm{H}$ & $\mathrm{Cd}, \mathrm{Ct}$ & {$[39,50,51]$} \\
\hline Acteoside (2) & $\mathrm{H}$ & Rha & $\mathrm{Cf}$ & $\mathrm{H}$ & $\mathrm{OH}$ & $\mathrm{OH}$ & $\mathrm{H}$ & $\mathrm{Cd}, \mathrm{Ct}$ & {$[39,50,51]$} \\
\hline Cistanoside A (3) & $\mathrm{H}$ & Rha & $\mathrm{Cf}$ & Glc & Ome & $\mathrm{OH}$ & $\mathrm{H}$ & $\mathrm{Cd}, \mathrm{Ct}$ & [39] \\
\hline Cistanoside B (4) & $\mathrm{H}$ & Rha & Fr & Glc & Ome & $\mathrm{OH}$ & $\mathrm{H}$ & $\mathrm{Cd}$ & {$[52]$} \\
\hline Cistanoside C (5) & $\mathrm{H}$ & Rha & $\mathrm{Cf}$ & $\mathrm{H}$ & Ome & $\mathrm{OH}$ & $\mathrm{H}$ & $\mathrm{Cd}$ & {$[52]$} \\
\hline Cistanoside D (6) & $\mathrm{H}$ & Rha & $\mathrm{Fr}$ & $\mathrm{H}$ & Ome & $\mathrm{OH}$ & $\mathrm{H}$ & $\mathrm{Cd}$ & {$[52]$} \\
\hline Cistanoside E (7) & $\mathrm{H}$ & Rha & $\mathrm{H}$ & $\mathrm{H}$ & Ome & $\mathrm{OH}$ & $\mathrm{H}$ & $\mathrm{Cd}$ & [52] \\
\hline Cistanoside G (8) & $\mathrm{H}$ & Rha & $\mathrm{H}$ & $\mathrm{H}$ & $\mathrm{H}$ & $\mathrm{OH}$ & $\mathrm{H}$ & $\mathrm{Cd}$ & {$[48]$} \\
\hline Cistanoside H (9) & Ac & Rha & $\mathrm{H}$ & $\mathrm{H}$ & $\mathrm{OH}$ & $\mathrm{OH}$ & $\mathrm{H}$ & $\mathrm{Cd}$ & [2] \\
\hline Decaffeoylacteoside (10) & $\mathrm{H}$ & Rha & $\mathrm{H}$ & $\mathrm{H}$ & $\mathrm{OH}$ & $\mathrm{OH}$ & $\mathrm{H}$ & $\mathrm{Cd}, \mathrm{Ct}$ & [49] \\
\hline Echinacoside (11) & $\mathrm{H}$ & Rha & $\mathrm{Cf}$ & Glc & $\mathrm{OH}$ & $\mathrm{OH}$ & $\mathrm{H}$ & $\mathrm{Cd}, \mathrm{Ct}$ & {$[39,48]$} \\
\hline Isoacteoside (12) & $\mathrm{H}$ & Rha & $\mathrm{H}$ & $\mathrm{Cf}$ & $\mathrm{OH}$ & $\mathrm{OH}$ & $\mathrm{H}$ & $\mathrm{Cd}, \mathrm{Ct}$ & {$[39,50,51]$} \\
\hline $\begin{array}{c}\text { Isosyringalide-3'- } \alpha \text {-L- } \\
\text { rhamnopyranoside (13) }\end{array}$ & $\mathrm{H}$ & Rha & $\mathrm{Cm}$ & $\mathrm{H}$ & $\mathrm{OH}$ & $\mathrm{OH}$ & $\mathrm{H}$ & $\mathrm{Ct}$ & [2] \\
\hline Osmanthuside (14) & $\mathrm{H}$ & Rha & $\mathrm{Cm}$ & $\mathrm{H}$ & $\mathrm{H}$ & $\mathrm{OH}$ & $\mathrm{H}$ & $\mathrm{Cd}$ & {$[53]$} \\
\hline Salidroside (15) & $\mathrm{H}$ & $\mathrm{H}$ & $\mathrm{H}$ & $\mathrm{H}$ & $\mathrm{H}$ & $\mathrm{OH}$ & $\mathrm{H}$ & $\mathrm{Cd}, \mathrm{Ct}$ & {$[49,54]$} \\
\hline $\begin{array}{c}\text { Syringalide A-3'- } \alpha \text {-L- } \\
\text { rhamnopyranoside (16) }\end{array}$ & $\mathrm{H}$ & Rha & $\mathrm{Cf}$ & $\mathrm{H}$ & $\mathrm{H}$ & $\mathrm{OH}$ & $\mathrm{H}$ & $\mathrm{Cd}, \mathrm{Ct}$ & {$[39,51]$} \\
\hline Tubuloside A (17) & Ac & Rha & $\mathrm{Cf}$ & Glc & $\mathrm{OH}$ & $\mathrm{OH}$ & $\mathrm{H}$ & $\mathrm{Cd}, \mathrm{Ct}$ & [50] \\
\hline Tubuloside B (18) & Ac & Rha & $\mathrm{H}$ & $\mathrm{Cf}$ & $\mathrm{OH}$ & $\mathrm{OH}$ & $\mathrm{H}$ & $\mathrm{Cd}, \mathrm{Ct}$ & {$[39,50]$} \\
\hline Tubuloside C (19) & Ac & TA-Rha & $\mathrm{Cf}$ & Glc & $\mathrm{OH}$ & $\mathrm{OH}$ & $\mathrm{H}$ & $\mathrm{Ct}$ & [2] \\
\hline Tubuloside D (20) & Ac & TA-Rha & $\mathrm{Cm}$ & Glc & $\mathrm{OH}$ & $\mathrm{OH}$ & $\mathrm{H}$ & $\mathrm{Ct}$ & [2] \\
\hline Tubuloside E (21) & Ac & TA-Rha & $\mathrm{Cm}$ & $\mathrm{H}$ & $\mathrm{OH}$ & $\mathrm{OH}$ & $\mathrm{H}$ & $\mathrm{Ct}$ & {$[2]$} \\
\hline Cistantubuloside A (22) & $\mathrm{H}$ & Rha & $\mathrm{Cf}$ & Glc & $\mathrm{H}$ & $\mathrm{OH}$ & $\mathrm{H}$ & $\mathrm{Ct}$ & {$[49]$} \\
\hline Cistantubuloside $\mathbf{B}_{1} / \mathbf{B}_{2}(\mathbf{2 3})$ & $\mathrm{H}$ & Rha & $\begin{array}{c}\mathrm{Cm} / \mathrm{c}- \\
\mathrm{Cm}\end{array}$ & Glc & $\mathrm{OH}$ & $\mathrm{OH}$ & $\mathrm{H}$ & $\mathrm{Ct}$ & [49] \\
\hline Kankanoside F (24) & $\mathrm{H}$ & Rha & $\mathrm{H}$ & Glc & $\mathrm{OH}$ & $\mathrm{OH}$ & $\mathrm{H}$ & $\mathrm{Ct}$ & [48] \\
\hline Kankanoside G (25) & $\mathrm{H}$ & Rha & $\mathrm{H}$ & $\mathrm{Cf}$ & $\mathrm{H}$ & $\mathrm{OH}$ & $\mathrm{H}$ & $\mathrm{Ct}$ & [48] \\
\hline Cistantubuloside $\mathrm{C}_{1} / \mathrm{C}_{2}(\mathbf{2 6})$ & $\mathrm{H}$ & Rha & $\mathrm{Cf}$ & Glc & $\mathrm{OH}$ & $\mathrm{OH}$ & $\mathrm{OH}(\mathrm{S} / \mathrm{R})$ & $\mathrm{Ct}$ & {$[55]$} \\
\hline Crenatoside (27) & & & & & & & & $\mathrm{Ct}$ & [2] \\
\hline Cistanoside F (28) & & & & & & & & $\mathrm{Ct}$ & {$[39,48,49]$} \\
\hline
\end{tabular}

a Cf: trans-caffeoyl; Cm: trans-coumaroyl; c-Cm: cis-coumaroyl; Glc: $\beta$-glucopyranose. Rha: $\alpha$-L-rhamnopyranose; TA-Rha: 2",3",4"-triacetyl- $\alpha$ L-rhamnopyranose; Ac: acetyl.

b Cd: C. deserticola; Ct: C. tubulosa

PhGs containing echinacoside could enhance the activity of superoxide dismutase (SOD) significantly in the serum and brain, decrease the MDA content of liver and serum, and improve the index of spleen and thymus [66]. Cistanche deserticola containing echinacoside significantly improved the visual ability of rats by reducing the severity of the developed signs of retinopathy and cataract. The effect of Cistanche deserticola on the learning ability may be associated with differences in their redox homeostasis [67]. Cistanche deserticola may improve mucosal tissue repair by stimulating intestinal epithelial cell proliferation and preventing cell death via up-regulation of TGF- $\beta$ [68]. 
Table 3. The function and mechanisms of echinacoside with anti-aging and anti-aging related effects.

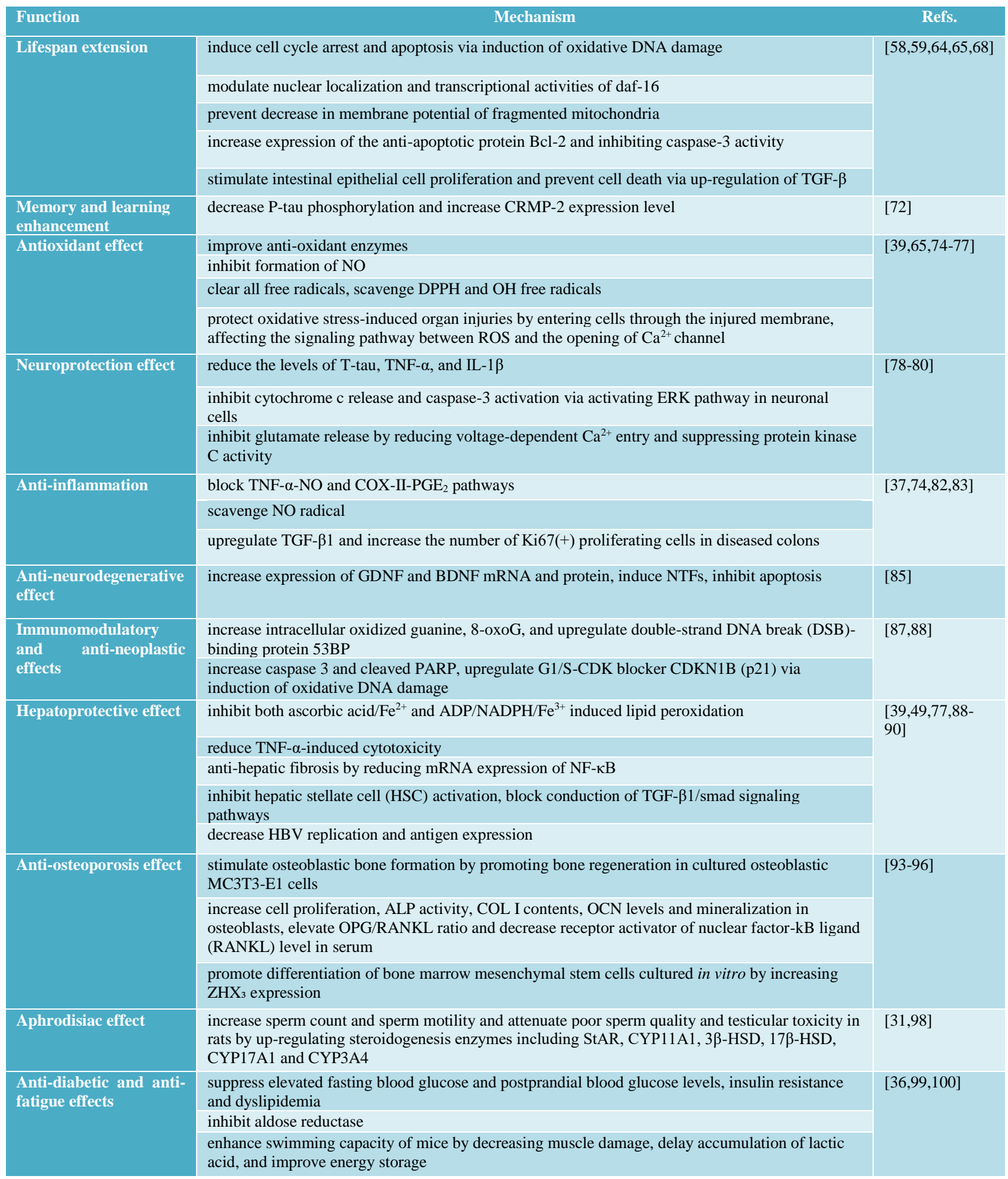


3.1.2 Memory and learning enhancement effects of echinacoside

The gradual loss of cognition is one of the main characteristics of aging $[69,70]$. It is recorded that PhGs containing echinacoside of Herb Cistanche could enhance the ability of learning and memorization [66]. P-tau is implicated in vascular dementia (VD) and AD because both share a common correlation with regards to vascular risk factors [71]. The glycosides of cistanche, which mainly contains echinacoside, plays a critical role in protecting hippocampal neurons in VD by decreasing Ptau phosphorylation and increasing collapsin response mediator protein-2 (CRMP-2) expression level [72]. Cistanche tubulosa glycoside capsules (CTG capsule, Memoregain $\left.{ }^{\circledR}\right)$ containing mainly echinacoside had a potential to be a possible treatment option for mild to moderate AD. Memoregain ${ }^{\circledR}$ capsules are effective and safe for the treatment of moderate $\mathrm{AD}$, which is in accordance with the ability of Cistanche tubulosa glycosides to inhibit excessive apoptosis of nerve cells. However, the mechanisms underlying the treatment of $\mathrm{AD}$ with Cistanche tubulosa glycosides are not only different from that of acetylcholinesterase inhibitors but also different from that of other types of traditional Chinese medicines. Antagonism of nerve cell apoptosis is a specific neuroprotective effect of Cistanche tubulosa glycosides [73].

\section{$\underline{\text { 3.1.3 Antioxidant effect of echinacoside }}$}

Echinacoside isolated from Herba Cistanches possesses free radical scavenging properties and protects oxidativestress-induced toxic injuries via different mechanisms. Recent studies proved the anti-oxidant activity of echinacoside, particularly in the clearing of all types of free radicals in vivo and in vitro $[39,74]$. Echinacoside improved the activity of anti-oxidant enzymes and inhibited the formation of lipid peroxide, MDA and NO [66, 74-76]. It possessed free radical scavenging properties [77] and was capable of protecting against oxidative stress-induced organ injuries, by entering cells through the injured membrane, affecting the signaling pathway between ROS and the opening of the $\mathrm{Ca}^{2+}$ channel [66].

\subsubsection{Neuroprotective effects of echinacoside}

Herba Cistanches containing echinacoside could improve cognitive and independent living abilities of moderate $\mathrm{AD}$ patients, reducing the levels of $\mathrm{T}$-tau, tumor necrosis factor- $\alpha$ (TNF- $\alpha)$, and interleukin-1 $\beta$ (IL-1 $\beta$ ) [78]. Transient treatment with echinacoside inhibited cytochrome $\mathrm{c}$ release and caspase- 3 activation caused by ensuing rotenone exposure via activation of Trkextracellular signal-regulated kinase (ERK) pathway in neuronal cells [79]. The inhibitory effect of echinacoside on evoked glutamate release was associated with reduced voltage-dependent $\mathrm{Ca}^{2+}$ entry and subsequent suppression of protein kinase $\mathrm{C}$ activity [80].

\subsubsection{Anti-inflammatory effects of echinacoside}

Aging in humans is associated with chronic low-grade inflammation (systemic) state characterized by an increase in pro-inflammatory markers including but not restricted to TNF- $\alpha$, IL-6, IL-1 $\beta$, and C-reactive protein [81]. Echinacoside possesses anti-inflammatory effects through scavenging the NO radical [74, 82]. Cistanche tubulosa extract markedly attenuated inflammatory signs by blocking the TNF- $\alpha-\mathrm{NO}$ and cyclooxygenase--IIprostaglandin E2 (COX-II-PGE $)_{2}$ pathways in carrageenan-induced air pouch inflammation [37]. Echinacoside protected the intestinal epithelium from inflammatory injury in DSS-induced colitis in mice by upregulating transforming growth factor (TGF)- $\beta 1$ as well as increasing the number of $\mathrm{Ki} 67^{(+)}$proliferating cells in diseased colons [83]. In addition, echinacoside significantly alleviated the inflammatory responses induced by 6-hydroxydopamine (6-OHDA) [63].

\subsubsection{Anti-neurodegenerative effect of echinacoside}

As echinacoside could cross the blood-brain barrier freely, it may have a promising potential in treating neurodegenerative diseases [79]; it acts as an antiinflammatory and neuroprotective agent [65]. PhGs might exert potential inhibitory effects on microglia-involved neuroinflammation, resulting in neuroprotection in inflammation related neuronal degenerative diseases including $\mathrm{AD}$ and $\mathrm{PD}[65,75,84]$. Additionally, echinacoside could increase expression of glial cell linederived neurotrophic factor (GDNF) and brain derived neurotrophic facto (BDNF) mRNA and protein, induce neurotrophic factors (NTFs) and inhibit apoptosis [85]. Echinacoside was demonstrated to increase viability of rat pheochromocytoma PC12 cells injured by $\mathrm{A} \beta$ and suppress the increase in intracellular ROS triggered by $\mathrm{A} \beta$. The interactions between echinacoside and amyloidforming proteins shed light on the protection of echinacoside against amyloid fibril-induced neuronal cell death [77]. The Cistanche tubulosa extract, which contains enough echinacoside, ameliorated the cognitive dysfunction caused by $A \beta$ 1-42 via blocking amyloid deposition especially in hippocampal areas [41].

3.1.7 Immunomodulatory and anti-neoplastic effects of echinacoside 
Extensive evidence exists indicating that aging in an organism is characterized with immune deficiency [86]. Echinacoside could be used as a specific immunostimulatory adjuvant against colorectal cancer [58]. Echinacoside caused a significant increase of intracellular oxidized guanine, 8-oxoG [87], a dramatic upregulation of the double-strand DNA break (DSB)- binding protein 53BP, induced cell cycle arrest and apoptosis, and significantly increased active caspase 3 and cleaved poly ADP-ribose polymerase (PARP). It upregulated the G1/S-CDK blocker CDKN1B (p21) in SW480 cancer cells via induction of oxidative DNA damage [58].

Table 4. The functions and mechanisms of acteoside with anti-aging and anti-aging related effects.

\begin{tabular}{|c|c|c|}
\hline Function & Mechanism & Refs. \\
\hline Lifespan extension & inhibit hepatic apoptosis & {$[49,101,102]$} \\
\hline \multirow{4}{*}{$\begin{array}{l}\text { Memory and learning } \\
\text { enhancement }\end{array}$} & promote NGF and its neuronal actions, increase TrK A expression, upregulate NGF & \multirow[t]{4}{*}[33,103-105]{} \\
\hline & inhibit acetylcholine esterase and increase the activities of antioxidant enzymes & \\
\hline & increase activity of GSH-Px, T-SOD, TChE and protein contents, and decrease MDA content & \\
\hline & $\begin{array}{l}\text { increase neurons and nissl bodies in the hippocampus, promote NGF and TrkA expression, } \\
\text { decrease the content of nitric oxide, activity of nitric oxide synthase and expression of caspase- } 3 \\
\text { protein }\end{array}$ & \\
\hline \multirow[t]{3}{*}{ Antioxidant effect } & scavenge NO radical and DPPH radical & \multirow{3}{*}{$\begin{array}{l}{[38,65,103,} \\
106,107]\end{array}$} \\
\hline & decrease activity of nitric oxide synthase & \\
\hline & $\begin{array}{l}\text { inhibit both ascorbic acid/ } / \mathrm{Fe}^{2+} \text { and } \mathrm{ADP} / \mathrm{NADPH} / \mathrm{Fe}^{3+} \text { induced lipid peroxidation in rat liver } \\
\text { microsomes }\end{array}$ & \\
\hline \multirow[t]{4}{*}{ Neuroprotective effect } & increase neurons and nissl bodies in the hippocampus & \multirow{4}{*}{$\begin{array}{l}{[41,103,104,} \\
108,109]\end{array}$} \\
\hline & inhibit rotenone-induced $\alpha$-synuclein, caspase-3 upregulation and MAP- 2 downregulation & \\
\hline & block amyloid deposition, reverse cholinergic and hippocampal dopaminergic neuronal function & \\
\hline & $\begin{array}{l}\text { improve SK-N-SH cell morphology, enhance cell survival rate, decrease cell LDH release rate } \\
\text { and expression of phosphorylated tau proteins at p-Ser } 199 / 202 \text { and p-Ser } 404 \text { sites, up-regulate } \\
\text { the expression of non-phosphorylated tau proteins at Ser } 202 \text { site and Ser } 404 \text { sites }\end{array}$ & \\
\hline $\begin{array}{l}\text { Anti-inflammatory } \\
\text { effect }\end{array}$ & scavenge NO radical & [74] \\
\hline \multirow{2}{*}{$\begin{array}{l}\text { Immunomodulatory } \\
\text { and anti-neoplastic } \\
\text { effects }\end{array}$} & inhibit basophilic cell-derived immediate-type and delayed-type allergic reactions & \multirow[t]{2}{*}[110,111]{} \\
\hline & $\begin{array}{l}\text { down-regulate expressions of the CCL1, CCL2, CCL3, CCL4, FCER1A and NFATC1 genes, } \\
\text { inhibit MAPK pathway, and decrease JNK phosphorylation }\end{array}$ & \\
\hline \multirow{6}{*}{$\begin{array}{l}\text { Hepatoprotective } \\
\text { effect }\end{array}$} & antioxidative, immunoregulatory, regulate hepatic apoptosis & \multirow{6}{*}{$\begin{array}{c}{[49,50,90,} \\
96,102]\end{array}$} \\
\hline & $\begin{array}{l}\text { inhibit TNF- } \alpha \text {-mediated hepatic apoptosis and subsequent necrosis in DGalN/LPS-induced liver } \\
\text { failure }\end{array}$ & \\
\hline & scavenge free radicals, inhibit lipid peroxidation, protect hepatic membranes & \\
\hline & block the TGF- $\beta 1 /$ smad signaling pathway and inhibit the activation of HSC & \\
\hline & $\begin{array}{l}\text { inhibit D-GalN-induced death of hepatocytes and reduce TNF- } \alpha \text {-induced cytotoxicity in L929 } \\
\text { cells }\end{array}$ & \\
\hline & block P450-mediated bioactivation & \\
\hline \multirow{2}{*}{$\begin{array}{l}\text { Anti- } \\
\text { hypercholesterolemia } \\
\text { and anti-diabetic } \\
\text { effects }\end{array}$} & $\begin{array}{l}\text { enhance mRNA expressions of apolipoprotein B, VLDL receptor, and cytochrome P450 SCC in } \\
\text { HepG2 hepatocytes, in diet-induced hypercholesterolemia mice }\end{array}$ & \multirow[t]{2}{*}[25,36]{} \\
\hline & improve glucose tolerance in starch-loaded mice & \\
\hline
\end{tabular}




\subsubsection{Hepatoprotection effects of echinacoside}

Echinacoside exhibited significant inhibition on both ascorbic acid/ $/ \mathrm{Fe}^{2+}$ and ADP/NADPH/ $/ \mathrm{Fe}^{3+}$ induced lipid peroxidation in rat liver microsomes, which were more potent than $\alpha$-tocopherol of caffeic acid [39]. It also inhibited D-GalN-induced death of hepatocytes and reduced TNF- $\alpha$-induced cytotoxicity in L929 cells [49]. It was reported that $\mathrm{PhGs}$ have significant anti-hepatic fibrosis effects by reducing NF- $\mathrm{B}$ RNA levels $[88,89]$. Echinacoside possesses an anti-hepatic fibrosis effect by inhibiting hepatic stellate cell (HSC) activation and the TGF- $\beta 1 /$ smad pathway (increasing the mRNA level and protein expression of smad7, and decreasing the mRNA levels of smad2, smad 3 and the protein expression of smad2, phospho-smad2, smad3, phospho-smad3) [89]. Echinacoside could also provide a definite protective effect against acute hepatic injury by ameliorating histopathological damage of the liver and the number of apoptotic hepatocytes, which was accompanied by the reduction of serum alanine aminotransferase (ALT), aspertate aminotransferase (AST) levels and hepatic MDA content as well as ROS production, and the restoration of hepatic SOD activity and glutathione (GSH) content [77]. Echinacoside also has a strong effect against hepatitis B virus (HBV) replication and antigen expression [90].

\subsubsection{Anti-osteoporosis effects of echinacoside}

Osteoporosis has already become one of the leading threats for the health of the aging population [91, 92]. Echinacoside, like estrogen, has a stimulatory effect on osteoblastic bone formation whereby it promotes bone regeneration in cultured osteoblastic MC3T3-E1 cells. It was effective and safe in treating ovariectomy (OVX)induced osteoporosis by increasing cell proliferation, alkaline phosphatase (ALP) activity, collagen type I (COL I) contents, osteocalcin $(\mathrm{OCN})$ levels and mineralization in osteoblasts, decreasing receptor activator of nuclear factor- $\kappa \mathrm{B}$ ligand (RANKL) level and elevating the osteoprotegerin (OPG)/RANKL ratio in serum [93-95]. In addition, echinacoside could promote the differentiation of bone marrow mesenchymal stem cells in vitro, and the mechanism may be correlated with the increase in the zinc fingers and homeoboxes $3\left(\mathrm{ZHX}_{3}\right)$ expression [96].

\subsubsection{Aphrodisiac effects of echinacoside}

There are different opinions about the safety of Herba Cistanches treatment for diseases involving the male reproductive system. Some studies showed that Herba Cistanches displayed cytotoxic effects on the male reproductive system, thus it may not be appropriate for therapies seeking to improve the function of the male reproductive system [97]. Other studies demonstrated that Echinacoside could increase sperm count and sperm motility, and attenuate poor sperm quality and testicular toxicity in rats through the up-regulation of steroidogenesis enzymes including steroidogenic acute regulatory protein (StAR), cytochrome $\mathrm{P} 450$ cholesterol

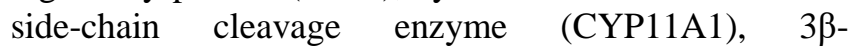
hydroxysteroid dehydrogenase (3 $\beta$-HSD), 17 $\beta$-HSD, CYP17A1 [98] and CYP3A4 [31].

\subsubsection{Anti-diabetic and anti-fatigue effects of echinacoside}

Cistanche tubulosa could significantly suppress elevated fasting blood glucose and postprandial blood glucose levels, improve insulin resistance and dyslipidemia, and suppress body weight loss in $\mathrm{db} / \mathrm{db}$ mice [99]. One study showed that echinacoside had potent aldose reductase inhibitory activity [100]. The phenylethanoid-rich extract of Cistanche deserticola Y.C. Ma containing echinacoside as its major constituent played an important role in antifatigue activity through enhancing the swimming capacity of mice by decreasing muscle damage, delaying the accumulation of lactic acid, and by improving energy storage [36].

\subsection{Acteoside (Verbascoside)}

Acteoside, also known as verbascoside or orobanchin, is another major active phenylethanoid glycoside present in Herba Cistanches. Its functions and mechanisms are summarized in Table 4.

\subsubsection{Lifespan extension by acteoside}

There are no direct reports about lifespan extension by acteoside. Previous studies have indicated that acteoside significantly improved cell viability via anti-apoptotic effects. Acteoside exhibits a significant inhibitory effect on hepatic apoptosis $[49,101,102]$. In addition, acteoside could improve learning and memory in a mouse model of senescence induced by a combination of D-galactose and $\mathrm{AlCl} 3$ [103]. It also improved the behavior in senescenceaccelerated OXYS rats [67].

\subsubsection{Memory and learning enhancement effects of acteoside}

Acteoside has been shown to have significant protective effects on learning and memory impairment in a mouse scopolamine-induced amnesia model through the increase in the activities of GSH-Px, T-SOD, total cholinesterase (TChE), and decreasing MDA content [103]. The 
mechanisms of memory enhancement of acteoside were partly due to inhibition of acetylcholine esterase and elevation of antioxidant enzymes [33]. Acteoside could decrease the activity of NO synthase and the expression of caspase-3 protein [104]. It also could promote the release of nerve growth factor (NGF) and neuronal actions, including neurite outgrowth and synapse formation, and increasing tropomycin receptor kinase A (TrkA) expression [105]. One clinic trial showed that Herba Cistanches containing acteoside could improve cognitive and independent living abilities of moderate AD patients [77].

\subsubsection{Antioxidant effect of acteoside}

Acteoside protects the cell from oxidative stress and scavenging of free radicals. As an antioxidant, acteoside could not only scavenge radical oxygen, such as NO radical and 1,1-diphenyl-2-picrylhydrazyl (DPPH) radical $[65,106]$, but also decrease the activity of NO synthase [103]. Acteoside showed stronger free radical scavenging activities than $\alpha$-tocopherol on DPPH radical and xanthine/xanthine oxidase generated superoxide anion radical $\mathrm{O}^{2-}$, and exhibited significant inhibition on both ascorbic acid/Fe $\mathrm{Fe}^{2+}$ and ADP/NADPH/ $/ \mathrm{Fe}^{3+}$ induced lipid peroxidation in rat liver microsomes [38]. The numbers of phenolic hydroxyl groups of phenylpropanoid glycosides are directly related to their scavenging activities. The scavenging activities are likely related to the odihydroxy group of phenylpropanoid glycosides as well [107].

\subsubsection{Neuroprotective effect of acteoside}

Recent studies indicated that acteoside could exhibit neuroprotective capabilities [104, 105]. Acteoside could increase the number of neurons and nissl bodies in the hippocampus [104]. Acteoside significantly attenuated Parkinsonism symptoms by inhibiting rotenone-induced $\alpha$-synuclein and caspase- 3 upregulation, and microtubuleassociated protein 2 downregulation in PD rats [108]. Acteoside ameliorated the cognitive dysfunction caused by A $\beta$ 1-42 via blocking amyloid deposition, reversing cholinergic and dopaminergic neuronal function [41]. In addition, acteoside has significant protective effect on a cellular model of AD induced by okadaic acid through improving SK-N-SH cell morphology, enhancing cell survival rate, decreasing cell lactate dehydrogenase release rate and the expression of phosphorylated tau proteins at the p-Ser 199/202 and p-Ser 404 sites, and upregulating the expression of non-phosphorylated tau proteins at the Ser 202 site and Ser 404 sites [109].

3.2.5 Anti-inflammatory effect of acteoside
Acteoside had an anti-inflammatory effect against Dgalactosamine/ lipopolysaccharide-induced hepatitis in mice [109], which was possibly related to its NO radicalscavenging activity [74].

3.2.6 Immunomodulatory and anti-neoplastic effects of acteoside

Acteoside is a potent immunostimulant with extensive effects on immune organs, immune cells and immune factors. It could inhibit basophilic cell-derived immediate-type and delayed-type allergic reactions. It was reported that acteoside inhibited the release of $\beta$ hexosaminidase and $\mathrm{Ca}^{2+}$ influx from immunoglobulin $\mathrm{E}-$ mediated RBL-2H3 cells. It inhibited histamine release, production of TNF- $\alpha$ and IL- 4 in human basophilic (KU812) cells [110]. The anti-allergy effects of acteoside were due to downregulation of the expressions of the chemokine ligand (CCL) 1, CCL2, CCL3, CCL4, Fc fragment of IgE, high affinity $\mathrm{I}$, receptor for alpha polypeptide (FCER1A), nuclear factor of activated $\mathrm{T}$ cell, cytoplasmic, and calcineurin-dependent 1 (NFATC1) genes and inhibition of the mitogen-activated protein kinase (MAPK) pathway through decreased C-jun N terminal kinase (JNK) phosphorylation [111]. Acteoside also exhibited inhibitory effects on the proliferation of the prostate cancer PC-3 cell line, which was roughly double the potency afforded by echinacoside [86].

\subsubsection{Hepatoprotective effect of acteoside}

The mode of action of acteoside in hepatic protection is at least in part related to its antioxidative, immunoregulatory properties and its ability to regulate hepatic apoptosis [96, 102]. Acteoside could effectively inhibit TNF- $\alpha$-mediated hepatic apoptosis and the subsequent necrosis in DGalN/LPS-induced liver failure. The protective effect of acteoside on immunological liver injury may be due to its ability to scavenge free radicals, inhibit lipid peroxidation, protect hepatic membranes, and restore the balance of Th1/Th2 and Bax/Bcl-2 [102]. The protective effects against carbon tetrachloride was possibly related to the acteoside's ability to block the P450-mediated bioactivation and scavenge free radicals during liver injury [50]. Acteoside also inhibited DGalN-induced death of hepatocytes and reduced TNF- $\alpha$-induced cytotoxicity in L929 cells [49]. Acteoside may be a potential herbal medicine for the treatment of liver fibrosis because of its ability to block the TGF- $\beta 1 / \mathrm{smad}$ signaling pathway and inhibit the activation of hepatic stellate cell [90].

3.2.8 Anti-hypercholesterolemia and anti-diabetic effects of acteoside 
Acteoside, acquired from the aqueous ethanol extract of the roots of Cistanche tubulosa, was involved in regulating the hypocholesterolemic activity through enhancing the mRNA expressions of apolipoprotein B, very low-density lipoprotein (VLDL) receptor, and cytochrome P450 SCC in HepG2 hepatocytes of hypercholesterolemia mice [25]. Acteoside was also found to significantly improve glucose tolerance in starch-loaded mice [36].

Table 5. The function and mechanisms of isoacteoside with anti-aging related effects.

\begin{tabular}{|c|c|c|}
\hline Function & Mechanism & Refs. \\
\hline Antioxidant effect & scavenge free radical such as NO radical & {$[39,74,83]$} \\
\hline \multirow[t]{2}{*}{ Hepatoprotective effect } & $\begin{array}{l}\text { inhibit both ascorbic acid/ } / \mathrm{Fe}^{2+} \text { and } \mathrm{ADP} / \mathrm{NADPH} / \mathrm{Fe}^{3+} \text { induced } \\
\text { lipid peroxidation in rat liver microsomes }\end{array}$ & {$[39,49]$} \\
\hline & reduce TNF- $\alpha$-induced cytotoxicity & \\
\hline Neuroprotective effect & inhibit microglia-involved neuroinflammation & [83] \\
\hline
\end{tabular}

\subsection{Isoacteoside}

Isoacteoside is one of the phenylethanoid compounds isolated from Herba Cistanches. Previous studies mainly focused on its anti-oxidant, anti-apoptotic, neuroprotective and hepatoprotective effects. Isoacteoside showed strong free radical scavenging activities [39, 74, 83] and hepatoprotective activity against either the radical generator carbon tetrachloride (CCl (4)) or specific liver toxin DGalN [49, 50]. The mechanisms of hepatoprotective effects were also related to its inhibitory effects on both ascorbic acid/ $\mathrm{Fe}^{2+}$ and $\mathrm{ADP} / \mathrm{NADPH} / \mathrm{Fe}^{3+}$ induced lipid peroxidation in rat liver microsomes [39]. It could also reduce TNF- $\alpha$-induced cytotoxicity in L929 cells [49]. In addition, isoacteoside was found to have potential inhibitory effects on microglia-involved neuroinflammation [83]. Its function and mechanisms are shown in Table 5.

\subsection{Pharmacological comparison of echinacoside, acteoside and isoacteoside}

Antioxidative effects were found to be potentiated by an increase in the number of phenolic hydroxyl groups in the molecule [39]. The anti-oxidative activity of PhGs is related to steric hindrance, the presence of 2-acetyl on the middle glucopyranose, the location and number of phenolic hydroxyls in the molecule. Additionally, it may be related to the $\alpha$-, $\beta$-unsaturated ketone of phenyl-2propenoyl [112]. Moreover, there is a certain dose-effect relationship in vivo with respect to the hepatoprotective effects of echinacoside, acteoside and isoacteoside [49]. The hepatoprotective or inhibition of HSC activity of acteoside is better than that of echinacoside, which may attribute to the presence of steric hindrance [90].

\section{Polysaccharides from Herba Cistanches}

Polysaccharides are compounds from the water or ethanol extract of Herba Cistanches. Studies found that polysaccharides from Cistanche deserticola have antihyperglycemic and hypolipidemic effects [99], immunological activity [113], proliferative effect on lymphocytes [114], antioxidant potential in vitro [115], and hepatoprotective activity [116]. They are potent for the stimulation of both T- and B-cell proliferation [117]. Their origin, functions, and mechanisms are found in Table 6.

\section{Extractions or bioactive components with potential anti-aging effects obtained from other species of Cistanches}

In recent years, the wild Cistanche deserticola Y.C. Ma and Cistanche tubulosa (Schrenk) R. Wight are close to being extinct due to over-harvesting, and thus need protection in China. Due to the deficiency of the natural resources of the official Herba Cistanche, other species of this genus such as the Cistanche salsa (C. A. Mey.) G. Beck and Cistanche violacea Desf. (Orobanchaceae) are also used as substitutes in many areas. Other Cistanches species have demonstrated potential anti-aging effects.

\subsection{Cistanche Salsa}

Cistanche salsa (C.A. Mey.) G. Beck, found in the 
provinces of northwest China, is also used in some regions due to the resource shortage. It was found that Cistanche deserticola Y.C. Ma and Cistanche salsa (C.A. Mey.) G. Beck were used as Herba Cistanches in traditional Chinese medicine according to the ancient herbal records. Its active ingredients, functions and mechanisms are summarized in Table 7.

\subsubsection{Anti-aging related effects of Cistanche Salsa $\underline{\text { extractions }}$}

The extract of Cistanche salsa significantly suppressed loss of bone weight in ovariectomized mice [118]. It may be a potential therapeutic candidate for benign prostate hyperplasia (BPH) owing to its ability to decrease prostate weight, serum dihydrotestosterone (DHT) concentration, and mRNA expression of $5 \alpha$-reductase type 1 and type 2 in prostate tissue of BPH-induced rats. It also suppressed cell proliferation by regulating the expression levels of inflammatory-related proteins (inducible NO synthase and cyclooxygenase 2 ) and apoptosis-associated proteins (caspase-3 and Bcl-2 family proteins) [119].

Table 6. Active ingredients, functions and mechanisms of Polysaccharides from Herba Cistanches with anti-aging related effects.

\begin{tabular}{|c|c|c|c|}
\hline Function & Active ingredient & Mechanism & Refs. \\
\hline \multirow{4}{*}{$\begin{array}{l}\text { Immunological } \\
\text { activity }\end{array}$} & ACDP-2 & stimulate immune response & [114] \\
\hline & $\begin{array}{l}\text { Cistanche } \\
\text { Deserticola } \\
\text { polysaccharide } \\
\text { (CDPS) }\end{array}$ & $\begin{array}{l}\text { stimulate the division of thymus } \\
\text { lymphocyte, promote thymus intracellular } \\
\text { calcium delivering }\end{array}$ & [113] \\
\hline & CDA-1A & stimulate B cell proliferation & [117] \\
\hline & CDA-3B & stimulate both $\mathrm{T}$ and $\mathrm{B}$ cell proliferation & [117] \\
\hline $\begin{array}{l}\text { Hepatoprotective } \\
\text { effect }\end{array}$ & $\mathrm{CDP}-\mathrm{C}$ & $\begin{array}{l}\text { antioxidant, promote viability of HepG } 2 \\
\text { cells, } \\
\text { attenuate microvesicular steatosis and mild } \\
\text { necrosis, reduce the contents of MDA and } \\
\text { TG }\end{array}$ & [116] \\
\hline Antioxidant activity & $\begin{array}{l}\text { Cistanche tubulosa } \\
\text { polysaccharide (CTP) }\end{array}$ & scavenge DPPH, OH and ABTS radical & [115] \\
\hline Anti-diabetic effect & $\begin{array}{l}\text { Cistanche tubulosa } \\
\text { polysaccharide (CTP) }\end{array}$ & $\begin{array}{l}\text { suppress elevated fasting blood glucose and } \\
\text { postprandial blood glucose levels, insulin } \\
\text { resistance and dyslipidemia } \\
\text { suppress body weight loss in db/db mice }\end{array}$ & [99] \\
\hline
\end{tabular}

\subsubsection{Anti-aging and anti-aging related effects of PhGs}

Like Cistanche deserticola and Cistanche tubulosa, PhGs are the major active components of Cistanche Salsa. It was reported that PhGs from Cistanches salsa could prevent cell apoptosis [120] and protect dopaminergic neurons against dopamine neurotoxicity induced by 1 methyl-4-phenyl-1,2,3,6-tetrahydropyridine (MPTP) in C57 mice [121]. Echinacoside, acteoside and tubuloside are major compounds of $\mathrm{PhGs}$ with significant pharmacological activities.

\subsubsection{Anti-aging and anti-aging related effects of} echinacoside

\subsubsection{Lifespan extension by echinacoside}

Echinacoside could improve ROS degradation [122] and retard human fibroblastic cellular senescence through protecting cells from DNA damage by triggering cells in the G1 phase to enter the S phase and G2 phase. In addition, echinacoside could protect neuronal cells from apoptosis [123] by maintaining mitochondrial function, decreasing the generation of ROS, increasing the expression of the anti-apoptotic protein $\mathrm{Bcl}-2$ and inhibiting caspase-3 activity through an antioxidative mechanism [124].

\subsubsection{Anti-inflammatory effect of echinacoside}


There was some evidence to support the antiinflammatory effect of echinacoside [125]. Echinacoside showed anti-inflammatory property, characterized by a significant reduction in the inflammatory markers, including myeloperoxidase, extracellular nucleosomes, high-mobility group box 1 , and inflammatory cytokines in the plasma of D-galactosamine and lipopolysaccharideinduced acute liver injury, which may be important mechanisms related to its protective effect [126].

Table 7. Active ingredients, functions and mechanisms of Cistanche Salsa with anti-aging and anti-aging related effects.

\begin{tabular}{|c|c|c|c|}
\hline Active ingredient & Function & Mechanism & Refs. \\
\hline \multirow{2}{*}{$\begin{array}{l}\text { Ethanol extract of } \\
\text { Cistanche Salsa }\end{array}$} & Anti-osteoporosis effect & suppress bone weight loss & [118] \\
\hline & $\begin{array}{l}\text { Anti-proliferative } \\
\text { effect }\end{array}$ & $\begin{array}{l}\text { decrease prostate weight, serum dihydrotestosterone concentration, and mRNA } \\
\text { expression of } 5 \alpha \text {-reductase type } 1 \text { and type } 2 \text {, regulate the expression levels of } \\
\text { inflammatory-related proteins and apoptosis-associated proteins }\end{array}$ & [119] \\
\hline $\begin{array}{l}\text { Phenylethanoid } \\
\text { glycosides (PhGs) }\end{array}$ & Neuroprotective effect & $\begin{array}{l}\text { prevent cell apoptosis, protect dopaminergic neurons against dopamine } \\
\text { neurotoxicity induced by MPTP }\end{array}$ & [120-121] \\
\hline \multirow[t]{17}{*}{ Echinacoside } & \multirow[t]{3}{*}{ Lifespan extension } & $\begin{array}{l}\text { protect cells from DNA damage, trigger cells in the G1 phase to enter the } \mathrm{S} \\
\text { phase and G2 phase, improve ROS degradation }\end{array}$ & \multirow[t]{3}{*}{ [122-124] } \\
\hline & & protect neuronal cells from apoptosis & \\
\hline & & $\begin{array}{l}\text { maintain mitochondrial function, decrease the generation of ROS, increase the } \\
\text { expression of the antiapoptotic protein Bcl- } 2 \text { and inhibit caspase- } 3 \text { activity }\end{array}$ & \\
\hline & $\begin{array}{l}\text { Anti-inflammatory } \\
\text { effect }\end{array}$ & $\begin{array}{l}\text { reduce inflammatory markers, including myeloperoxidase, extracellular } \\
\text { nucleosomes, high-mobility group box } 1 \text {, and inflammatory cytokines }\end{array}$ & [126] \\
\hline & \multirow[t]{4}{*}{ Neuroprotective effect } & inhibit caspase- 3 and caspase- 8 activation in cerebellar granule neurons & \multirow[t]{4}{*}[127-130]{} \\
\hline & & $\begin{array}{l}\text { reduce ROS production, attenuate neurotoxicity mitochondrial dysfunction and } \\
\text { inflammatory responses induced by 6-OHDA }\end{array}$ & \\
\hline & & $\begin{array}{l}\text { suppress expression of apoptotic genes } \\
\text { inhibit generation of } \mathrm{MPP}^{+} \text {-induced ROS }\end{array}$ & \\
\hline & & decrease striatal extracellular levels of DA, DOPAC and HVA & \\
\hline & \multirow{6}{*}{$\begin{array}{l}\text { Anti-neurodegenerative } \\
\text { effect }\end{array}$} & attenuate neurotoxicity mitochondrial dysfunction and inflammatory responses & \multirow{6}{*}{$\begin{array}{r}{[123,125,} \\
127-128]\end{array}$} \\
\hline & & suppress dopaminergic neuron loss caused by $\mathrm{MPP}^{+}$or MPTP & \\
\hline & & maintain dopamine content and dopamine metabolite content & \\
\hline & & increase striatal dopamine and dopamine metabolite levels & \\
\hline & & $\begin{array}{l}\text { inhibit apoptosis and activation of microglia and astrocytes in the substantia } \\
\text { nigra }\end{array}$ & \\
\hline & & regulate cytokines such as $\mathrm{p} 38 \mathrm{MAPK}$ and NF-kB p52 subunit & \\
\hline & Anti-oxidant effect & decrease generation of ROS and protect oxidative-stress-induced toxic injuries & [124] \\
\hline & \multirow[t]{2}{*}{ Anti-neoplastic effect } & inhibit prostate cancer cell proliferation & \multirow[t]{2}{*}[132,133]{} \\
\hline & & modulate MAPK activity & \\
\hline \multirow[t]{3}{*}{ Acteoside } & \multirow[t]{2}{*}{ Skin-protective effect } & $\begin{array}{l}\text { enhance scavenging activity of ROS, decrease Bax/Bcl-2 ratio and } \\
\text { downregulate activity of pro caspase- } 3\end{array}$ & \multirow[t]{2}{*}{ [135] } \\
\hline & & modulate the MAPK signaling pathway & \\
\hline & Neuroprotective effect & inhibit neuronal death induced by $\mathrm{MPP}^{+}$and glutamate & {$[134]$} \\
\hline Tubuloside B & Neuroprotective effect & $\begin{array}{l}\text { inhibit cell apoptosis, attenuate MPP }{ }^{+} \text {induced cytotoxicity, DNA fragmentation, } \\
\text { and intracellular accumulation of ROS, anti-oxidative stress effects, } \\
\text { maintenance of mitochondria function, decrease of concentration of free } \\
\text { intracellular calcium, inhibition of caspase- } 3 \text { activity }\end{array}$ & {$[136,137]$} \\
\hline $\begin{array}{l}\text { (2E,6R)-8-Hydroxy- } \\
\text { 2,6-dimethyl-2- } \\
\text { octenoic acid [(R)- } \\
\text { HDOA] }\end{array}$ & Anti-osteoporosis effect & decrease bone weight and mechanical strength & [133] \\
\hline
\end{tabular}

\subsubsection{Neuroprotective effect of echinacoside}

Echinacoside significantly inhibited caspase-3 and caspase-8 activation in cerebellar granule neurons [127], reduced ROS production, attenuated neurotoxicity mitochondrial dysfunction and inflammatory responses 
induced by 6-OHDA [128]. In addition, echinacoside significantly improved neuroblastoma cell survival by inhibiting the generation of $\mathrm{MPP}^{+}$-induced ROS by suppressing the expression of apoptotic genes (ATF3, CHOP and SCNA) [129]. Echinacoside could protect dopaminergic neurons through significantly decreasing striatal extracellular levels of dopamine, 3,4-dihydroxyphenylacetic acid (DOPAC) and catabolites homovanillic acid (HVA) [130].

\subsubsection{Anti-neurodegenerative effect of echinacoside}

Modern pharmacological studies determined that echinacoside significantly improves learning and memory [125]. Mitochondrial dysfunction and inflammatory responses are involved in the mechanism of cell damage in neurodegenerative diseases. One study demonstrated that echinacoside significantly attenuated neurotoxicity mitochondrial dysfunction and inflammatory responses [128]. It also significantly suppressed dopaminergic neuronal loss caused by $\mathrm{MPP}^{+}$[127] or MPTP and maintained dopamine content and dopamine metabolite content compared with those measured in mice with MPTP-induced damage [127]. In addition, echinacoside inhibited the apoptosis and activation of microglia and astrocytes in the substantia nigra, which suggested its involvement in the regulation of neuro-inflammation through cytokines such as p38 MAPK and the NF- $\kappa$ B p52 subunit [123].

\subsubsection{Antioxidant effect of echinacoside}

It was reported that echinacoside with antioxidative properties could inhibit apoptosis by decreasing the generation of ROS and protecting from oxidative-stressinduced toxic injuries [124]. Echinacoside could also provide a protective effect against acute hepatic injury caused by $\mathrm{CCl}(4)$ in rats, which may be associated with its antioxidative effect [131].

\subsubsection{Anti-neoplastic effect of echinacoside}

One study showed that echinacoside exhibited an inhibitory effect on prostate cancer cell proliferation [132]. Echinacoside also markedly repress the proliferation of pancreatic adenocarcinoma cells by inducing the production of ROS and the perturbation of the mitochondrial membrane potential thus triggering apoptosis. Furthermore, it was elucidated that echinacoside inhibits tumor cell growth through modulating MAPK activity [133].

5.1.4 Anti-aging and anti-aging related effects of $\underline{\text { acteoside }}$
One study reported that the strength of the antioxidative activity of acteoside was better than that of echinacoside in Cistanche salsa. Acteoside from Cistanche salsa was shown to inhibit neuronal cell death induced by $\mathrm{MPP}^{+}$and glutamate [134]. Acteoside could protect the cells from Xray induced damage through enhancing the scavenging activity of ROS, decreasing the $\mathrm{Bax} / \mathrm{Bcl}-2$ ratio, downregulating the activity of pro caspase-3, and modulating the MAPK signaling pathway [135].

5.1.5 Anti-aging and anti-aging related effects of tubuloside B

Tubuloside $\mathrm{B}$ is one of the phenylethanoid compounds isolated from Cistanche salsa. It has neuroprotective effects against $\mathrm{MPP}^{+}$toxicity by inhibiting $\mathrm{MPP}^{+}$induced apoptosis and oxidative stress [136], and against TNF- $\alpha$ induced apoptosis in SH-SY5Y cells via anti-oxidative stress effects, maintenance of mitochondria function, decrease of concentration of free intracellular calcium and inhibition of caspase-3 activity [137].

The antioxidative effect was found to be potentiated by an increase in the number of phenolic hydroxyl groups in the molecule. The sequence of the strength of the antioxidative activity of the four components is as follows: Acteoside $\geq$ Tubuloside B $\geq$ Isoacteoside $>$ Echinacoside [127].

\subsubsection{Anti-aging related effects of monoterpene in} Cistanche Salsa

(2E,6R)-8-Hydroxy-2,6-dimethyl-2-octenoic acid [(R)HDOA], a novel monoterpene from Cistanche salsa, suppressed the decrease of bone weight and the mechanical strength in ovariectomized mice, and was found to be an anti-osteoporotic compound [133].

\subsection{Cistanche violacea Desf.}

Cistanche violacea, an endemic shrub in Northern Africa, is a holoparasitic plant found on Chenopodiaceae and Limoniastrum. The anti-inflammatory activity of $\mathrm{C}$. violacea ethanol extract probably inhibited arthritic activity and lysosomal release, which might be influenced by the synergistic action of iridoids, phenylethanoids glycosides and apigenin compounds [138].

\section{Conclusion}

Contemporary pharmacological studies have gradually validated Herba Cistanches' traditional uses. The crude extracts and compounds such as Phenylethanoid glycosides, acteoside, isoacteoside, echinacoside and tubuloside B from the stem have been shown to possess 
multiple medical functions especially for bone metabolism, the reproductive system, immune system and central nervous system in in vitro and in vivo studies. In view of its evident therapeutic efficiency and economic advantages, it may be beneficial to develop the active ingredients of Herba Cistanches as new pharmaceutical agents for the treatment of various diseases.

However, the exact chemical compound responsible for the observed pharmacological effects is still not known. The monomeric constituents of Herba Cistanches should therefore be investigated further to gain a better understanding of the individual components' pharmacological mechanisms. In addition, clinical studies in humans are urgently needed to confirm the claims of conventional phytotherapy. The side effects and potential interactions between Herba Cistanches and other synthetic drugs should also be further investigated. These may be important future challenges in drug discovery.

\section{Acknowledgments}

This research was supported by the Capital Characteristic Clinical Application Research of China (No. Z131107002213151) and High-Level Health Technical Personnel of the Beijing Health System (No. 2014-3-050).

\section{References}

[1] Li X, Zhang TC, Qiao Q, Ren Z, Zhao J, Yonezawa $\mathrm{T}$, et al. (2013). Complete chloroplast genome sequence of holoparasite Cistanche deserticola (Orobanchaceae) reveals gene loss and horizontal gene transfer from its host Haloxylon ammodendron (Chenopodiaceae). PLoS One, 8: e58747

[2] Jiang Y, Tu PF (2009). Analysis of chemical constituents in Cistanche species. J Chromatogr A, 1216: $1970-1979$

[3] Plant Institute of Chinese Academy of Science. Taxonomical Index of Chinese Higher Plants. Publisher of Science: Beijing; 1994

[4] Jiangsu New Medical College. Dictionary of Traditional Chinese Drugs (upper volume). Shanghai Scientific \& Technologic Publisher: Shanghai; 1997

[5] Pharmacopoeia, N.C.O.C. Pharmacopoeia of the People's Republic of China. The Chemical Industry Publishing House: Beijing; 2000

[6] Pharmacopoeia, N.C.O.C. Pharmacopoeia of the People's Republic of China. The Chemical Industry Publishing House: Beijing; 2005

[7] Zhang CZ, Wang SX, Zhang Y, Chen JP, Liang XM (2005). In vitro estrogenic activities of Chinese medicinal plants traditionally used for the management of menopausal symptoms. J Ethnopharmacol, 98: 295-300

[8] Argyropoulou A, Aligiannis N, Trougakos IP, Skaltsounis AL (2013). Natural compounds with anti-ageing activity. Nat Prod Rep, 30: 1412-1437
Tacutu R, Craig T, Budovsky A, Wuttke D, Lehmann G, Taranukha D, et al. (2013). Human Ageing Genomic Resources: integrated databases and tools for the biology and genetics of ageing. Nucleic Acids Res, 41: D1027-1033

[10] Rizvi S, Raza ST, Mahdi F (2014). Telomere length variations in aging and age-related diseases. Curr Aging Sci, 7: 161-167

[11] Yin D, Chen K (2005). The essential mechanisms of aging: Irreparable damage accumulation of biochemical side-reactions. Exp Gerontol, 40: 455465

[12] Onyango IG, Dennis J, Khan SM (2016). Mitochondrial dysfunction in Alzheimer's disease and the rationale for bioenergetics based therapies. Aging Dis, 7: 201-214

[13] Sesti F (2016). Oxidation of $K(+)$ channels in aging and neurodegeneration. Aging Dis, 7: 130-135

[14] Harman D (1956). Aging: a theory based on free radical and radiation chemistry. J Gerontol, 11: 298300

[15] Fulop T, Witkowski JM, Pawelec G, Alan C, Larbi A (2014). On the immunological theory of aging. Interdiscip Top Gerontol, 39: 163-176

[16] Navarrete-Reyes AP, Montana-Alvarez M (2009). Inflammaging. Aging inflammatory origin. Rev Invest Clin, 61: 327-336

Weinert BT, Timiras PS (2003). Invited review: Theories of aging. J Appl Physiol (1985), 95: 17061716

[18] Konar A, Singh P, Thakur MK (2016). Ageassociated cognitive decline: insights into molecular switches and recovery avenues. Aging Dis, 7: 121129

[19] Luo SF (1986). Chemical constituents of Cistanche deserticola. Zhong Yao Tong Bao, 11: 41-42

[20] Liu FC (1984). Effects of Epimedium sagittatum and Cistanche deserticola on DNA synthesis in "Yanginsufficiency" animal model induced by hydroxyurea. Zhong Xi Yi Jie He Za Zhi, 4: 488-490

Zhang HQ, Zhang AX (1988). Effects of Cistanche deserticola on immune function in mice. Zhong Xi Yi Jie He Za Zhi, 8: 736-737, 710

Tu PF, He YP, Lou ZC (1994). Herbalogical studies on rou congrong (herba Cistanchis). Zhongguo Zhong Yao Za Zhi, 19: 3-5, 61

Zhang K, Ma X, He W, Li H, Han S, Jiang Y, et al. (2014). Extracts of Cistanche deserticola can antagonize immunosenescence and extend life span in senescence-accelerated mouse prone 8 (SAM-P8) mice. Evid Based Complement Alternat Med, 2014: 601383

[24] Lin LW, Hsieh MT, Tsai FH, Wang WH, Wu CR (2002). Anti-nociceptive and anti-inflammatory activity caused by Cistanche deserticola in rodents. $\mathrm{J}$ Ethnopharmacol, 83: 177-182

[25] Shimoda H, Tanaka J, Takahara Y, Takemoto K, Shan SJ, Su MH (2009). The hypocholesterolemic effects of Cistanche tubulosa extract, a Chinese traditional crude medicine, in mice. Am J Chin Med, 


\section{7: $1125-1138$}

[26] Shin K, Kim TS, Kyung J, Kim D, Park D, Choi EK, et al. (2015). Effectiveness of the combinational treatment of Laminaria japonica and Cistanche tubulosa extracts in hair growth. Lab Anim Res, 31: 24-32

[27] Seok J, Kim TS, Kwon HJ, Lee SP, Kang MH, Kim BJ, et al. (2015). Efficacy of Cistanche tubulosa and Laminaria japonica extracts (MK-R7) supplement in preventing patterned hair loss and promoting scalp health. Clin Nutr Res, 4: 124-131

[28] Zong G, He W, Wu G, Chen M, Shen X, Shi M (1996). Comparison between Cistanche deserticola Y. C. Ma and C, tubulosa (Shenk) Wight on some pharmacological actions. Zhongguo Zhong Yao Za Zhi, 21: 436-437 inside backcover

[29] He W, Shu X, Zong G, Shi M, Xiong Y, Chen M (1996). Kidney reinforcing and yang supporting action of cistanche deserticola Y. C. Ma before and after preparation. Zhongguo Zhong Yao Za Zhi, 21: 534-537, 575

[30] Gu L, Xiong WT, Zhuang YL, Zhang JS, Liu X (2016). Effects of Cistanche deserticola extract on penis erectile response in castrated rats. Pak J Pharm Sci, 29: 557-562

[31] Wang T, Chen C, Yang M, Deng B, Kirby GM, Zhang X (2016). Cistanche tubulosa ethanol extract mediates rat sex hormone levels by induction of testicular steroidgenic enzymes. Pharm Biol, 54: 481487

[32] Wong HS, Ko KM (2013). Herba Cistanches stimulates cellular glutathione redox cycling by reactive oxygen species generated from mitochondrial respiration in $\mathrm{H} 9 \mathrm{c} 2$ cardiomyocytes. Pharm Biol, 51: 64-73

[33] Choi JG, Moon M, Jeong HU, Kim MC, Kim SY, Oh MS (2011). Cistanches Herba enhances learning and memory by inducing nerve growth factor. Behav Brain Res, 216: 652-658

[34] Yu Q, Li X, Cao X (2016). Cardioprotective effects of phenylethanoid glycoside-rich extract from Cistanche deserticola in ischemia-reperfusioninduced myocardial infarction in rats. Ann Vasc Surg, 34: 234-242

[35] Lu MC (1998). Studies on the sedative effect of Cistanche deserticola. J Ethnopharmacol, 59: 161165

[36] Cai RL, Yang MH, Shi Y, Chen J, Li YC, Qi Y (2010). Antifatigue activity of phenylethanoid-rich extract from Cistanche deserticola. Phytother Res, 24: 313-315

[37] Kyung J, Kim D, Park D, Yang YH, Choi EK, Lee SP, et al. (2012). Synergistic anti-inflammatory effects of Laminaria japonica fucoidan and Cistanche tubulosa extract. Lab Anim Res, 28: 91-97

[38] Wat E, Ng CF, Koon CM, Wong EC, Tomlinson B, Lau CB (2016). The protective effect of Herba Cistanches on statin-induced myotoxicity in vitro. $\mathrm{J}$ Ethnopharmacol, 190: 68-73

[39] Xiong Q, Kadota S, Tani T, Namba T (1996).
Antioxidative effects of phenylethanoids from Cistanche deserticola. Biol Pharm Bull, 19: 15801585

[40] Jia Y, Guan Q, Guo Y, Du C (2012). Reduction of inflammatory hyperplasia in the intestine in colon cancer-prone mice by water-extract of Cistanche deserticola. Phytother Res, 26: 812-819

[41] Wu CR, Lin HC, Su MH (2014). Reversal by aqueous extracts of Cistanche tubulosa from behavioral deficits in Alzheimer's disease-like rat model: relevance for amyloid deposition and central neurotransmitter function. BMC Complement Altern Med, 14: 202

[42] Liang H, Yu F, Tong Z, Huang Z (2011). Effect of Cistanches Herba aqueous extract on bone loss in ovariectomized rat. Int J Mol Sci, 12: 5060-5069 Liang HD, Yu F, Tong ZH, Zhang HQ, Liang W (2013). Cistanches Herba aqueous extract affecting serum BGP and TRAP and bone marrow Smad1 mRNA, Smad5 mRNA, TGF-beta1 mRNA and TIEG1 mRNA expression levels in osteoporosis disease. Mol Biol Rep, 40: 757-763

[44] Li TM, Huang HC, Su CM, Ho TY, Wu CM, Chen WC, et al. (2012). Cistanche deserticola extract increases bone formation in osteoblasts. J Pharm Pharmacol, 64: 897-907

[45] Gu L, Xiong WT, Wang C, Sun HX, Li GF, Liu X (2013). Cistanche deserticola decoction alleviates the testicular toxicity induced by hydroxyurea in male mice. Asian J Androl, 15: 838-840

[46] Li J, Huang D, He L (2014). Effect of roucongrong (Herba Cistanches Deserticolae) on reproductive toxicity in mice induced by glycoside of Leigongteng (Radix et Rhizoma Tripterygii). J Tradit Chin Med, 34: 324-328

[47] Siu AH, Ko KM (2010). Herba Cistanche extract enhances mitochondrial glutathione status and respiration in rat hearts, with possible induction of uncoupling proteins. Pharm Biol, 48: 512-517

Yoshikawa M, Matsuda H, Morikawa T, Xie H, Nakamura S, Muraoka O (2006). Phenylethanoid oligoglycosides and acylated oligosugars with vasorelaxant activity from Cistanche tubulosa. Bioorg Med Chem, 14: 7468-7475

[49] Morikawa T, Pan Y, Ninomiya K, Imura K, Matsuda H, Yoshikawa M, et al. (2010). Acylated phenylethanoid oligoglycosides with hepatoprotective activity from the desert plant Cistanche tubulosa. Bioorg Med Chem, 18: 18821890

[50] Xiong Q, Hase K, Tezuka Y, Tani T, Namba T, Kadota S (1998). Hepatoprotective activity of phenylethanoids from Cistanche deserticola. Planta Med, 64: 120-125

[51] Han L, Ji L, Boakye-Yiadom M, Li W, Song X, Gao $X$ (2012). Preparative isolation and purification of four compounds from Cistanches deserticola Y.C. Ma by high-speed counter-current chromatography. Molecules, 17: 8276-8284

[52] Li Y, Peng Y, Wang M, Zhou G, Zhang Y, Li X 
(2016). Rapid screening and identification of the differences between metabolites of Cistanche deserticola and $C$. tubulosa water extract in rats by UPLC-Q-TOF-MS combined pattern recognition analysis. J Pharm Biomed Anal, 131: 364-372

[53] Wang YM, Zhang SJ, Luo GA, Hu YN, Hu JP, Liu L, et al. (2000). Analysis of phenylethanoid glycosides in the extract of herba Cistanchis by LC/ESI-MS/MS. Yao Xue Xue Bao, 35: 839-842

[54] Yu P, Hu C, Meehan EJ, Chen L (2007). X-ray crystal structure and antioxidant activity of salidroside, a phenylethanoid glycoside. Chem Biodivers, 4: 508-513

[55] Tu PF, Song ZH, Shi HM, Yong J, Zhao YY (2006). Arylethyl (=Phenylethannoid) glycosides and oligosaccharide from the stem of Cistanche tubulosa. Helvetica Chimica Acta, 89: 927-935

[56] Cai H, Bao Z, Jiang Y, Wang XY, Fan XT, Aierken M, et al. (2007). Study on processing method of Cistanche tubulosa. Zhongguo Zhong Yao Za Zhi, 32: 1289-1291

[57] Cortopassi GA, Shibata D, Soong NW, Arnheim N (1992). A pattern of accumulation of a somatic deletion of mitochondrial DNA in aging human tissues. Proc Natl Acad Sci U S A, 89: 7370-7374

[58] Dong L, Yu D, Wu N, Wang H, Niu J, Wang Y, et al. (2015). Echinacoside induces apoptosis in human SW480 colorectal cancer cells by induction of oxidative DNA damages. Int J Mol Sci, 16: 1465514668

[59] Wang X, Zhang J, Lu L, Zhou L (2015). The longevity effect of echinacoside in Caenorhabditis elegans mediated through daf-16. Biosci Biotechnol Biochem, 79: 1676-1683

[60] Lopez-Otin C, Blasco MA, Partridge L, Serrano M, Kroemer G (2013). The hallmarks of aging. Cell, 153: 1194-1217

[61] Newgard CB, Pessin JE (2014). Recent progress in metabolic signaling pathways regulating aging and life span. J Gerontol A Biol Sci Med Sci, 69 Suppl 1: S21-27

[62] Harman D (1972). Free radical theory of aging: dietary implications. Am J Clin Nutr, 25: 839-843

[63] Larsson NG (2010). Somatic mitochondrial DNA mutations in mammalian aging. Annu Rev Biochem, 79: 683-706

[64] Zhu M, Zhou M, Shi Y, Li WW (2012). Effects of echinacoside on MPP(+)-induced mitochondrial fragmentation, mitophagy and cell apoptosis in $\mathrm{SH}$ SY5Y cells. Zhong Xi Yi Jie He Xue Bao, 10: 14271432

[65] Kuang R, Sun Y, Yuan W, Lei L, Zheng X (2009). Protective effects of echinacoside, one of the phenylethanoid glycosides, on $\mathrm{H}(2) \mathrm{O}(2)$-induced cytotoxicity in PC12 cells. Planta Med, 75: 14991504

[66] Xuan GD, Liu CQ (2008). Research on the effect of phenylethanoid glycosides (PEG) of the Cistanche deserticola on anti-aging in aged mice induced by $\mathrm{D}$ galactose. Zhong Yao Cai, 31: 1385-1388
[67] Stefanova NA, Fursova A, Sarsenbaev KN, Kolosova NG (2011). Effects of Cistanche deserticola on behavior and signs of cataract and retinopathy in senescence-accelerated OXYS rats. J Ethnopharmacol, 138: 624-632

[68] Jia Y, Guan Q, Guo Y, Du C (2012). Echinacoside stimulates cell proliferation and prevents cell apoptosis in intestinal epithelial MODE-K cells by up-regulation of transforming growth factor-beta1 expression. J Pharmacol Sci, 118: 99-108

[69] Keller JN (2006). Age-related neuropathology, cognitive decline, and Alzheimer's disease. Ageing Res Rev, 5: 1-13

[70] Medina M, Avila J (2014). New perspectives on the role of tau in Alzheimer's disease. Implications for therapy. Biochem Pharmacol, 88: 540-547

[71] Ning M, Zhang Z, Chen Z, Zhao T, Zhang D, Zhou $\mathrm{D}$, et al. (2011). Genetic evidence that vascular dementia is related to Alzheimer's disease: genetic association between tau polymorphism and vascular dementia in the Chinese population. Age Ageing, 40: 125-128

[72] Chen J, Zhou SN, Zhang YM, Feng YL, Wang S (2015). Glycosides of cistanche improve learning and memory in the rat model of vascular dementia. Eur Rev Med Pharmacol Sci, 19: 1234-1240

[73] Guo Q, Zhou Y, Wang CJ, Huang YM, Lee YT, Su MH, et al. (2013). An open-label, nonplacebocontrolled study on Cistanche tubulosa glycoside capsules (Memoregain $((\mathrm{R}))$ ) for treating moderate Alzheimer's Disease. Am J Alzheimers Dis Other Demen, 28: 363-370

[74] Xiong Q, Tezuka Y, Kaneko T, Li H, Tran LQ, Hase $\mathrm{K}$, et al. (2000). Inhibition of nitric oxide by phenylethanoids in activated macrophages. Eur $\mathbf{J}$ Pharmacol, 400: 137-144

Wang X, Li L, Muhuyati, Du N (1998). Antioxidative action of the glycosides of Cistanche in the tissue of mice. Zhongguo Zhong Yao Za Zhi, 23: 554-555, inside back cover

[76] Kuang R, Sun Y, Zheng X (2010). Suppression of nitric oxide implicated in the protective effect of echinacoside on $\mathrm{H} 2 \mathrm{O} 2$-induced $\mathrm{PC} 12$ cell injury. Nat Prod Commun, 5: 571-574

[77] Zhang D, Li H, Wang JB (2015). Echinacoside inhibits amyloid fibrillization of HEWL and protects against Abeta-induced neurotoxicity. Int $\mathrm{J}$ Biol Macromol, 72: 243-253

[78] Li N, Wang J, Ma J, Gu Z, Jiang C, Yu L, et al. (2015). Neuroprotective effects of Cistanches herba therapy on patients with moderate Alzheimer's disease. Evid Based Complement Alternat Med, 2015: 103985

[79] Zhu M, Lu C, Li W (2013). Transient exposure to echinacoside is sufficient to activate Trk signaling and protect neuronal cells from rotenone. J Neurochem, 124: 571-580

[80] Lu CW, Lin TY, Huang SK, Wang SJ (2016). Echinacoside inhibits glutamate release by suppressing voltage-dependent $\mathrm{Ca}(2+)$ entry and protein kinase $\mathrm{C}$ in rat cerebrocortical nerve 
terminals. Int J Mol Sci, 17:1006

[81] Panickar KS, Jewell DE (2015). The beneficial role of anti-inflammatory dietary ingredients in attenuating markers of chronic low-grade inflammation in aging. Horm Mol Biol Clin Investig, 23: $59-70$

[82] Nan ZD, Zeng KW, Shi SP, Zhao MB, Jiang Y, Tu PF (2013). Phenylethanoid glycosides with antiinflammatory activities from the stems of Cistanche deserticola cultured in Tarim desert. Fitoterapia, 89: 167-174

[83] Jia Y, Guan Q, Jiang Y, Salh B, Guo Y, Tu P, et al. (2014). Amelioration of dextran sulphate sodiuminduced colitis in mice by echinacoside-enriched extract of Cistanche tubulosa. Phytother Res, 28: 110-119

[84] Feng XY, Zhu M, Zhang QQ, Chen YP, Li WW (2012). Selective protection of nigral dopaminergic neurons by echinacoside in a rat model of Parkinson disease induced by rotenone. Zhong Xi Yi Jie He Xue Bao, 10: 777-783

[85] Zhao Q, Gao J, Li W, Cai D (2010). Neurotrophic and neurorescue effects of Echinacoside in the subacute MPTP mouse model of Parkinson's disease. Brain Res, 1346: 224-236

[86] Franceschi C, Bonafe M, Valensin S, Olivieri F, De Luca M, Ottaviani E, et al. (2000). Inflamm-aging. An evolutionary perspective on immunosenescence. Ann N Y Acad Sci, 908: 244-254

[87] Dong L, Wang H, Niu J, Zou M, Wu N, Yu D, et al. (2015). Echinacoside induces apoptotic cancer cell death by inhibiting the nucleotide pool sanitizing enzyme MTH1. Onco Targets Ther, 8: 3649-3664

[88] You SP, Zhao J, Ma L, Tudimat M, Zhang SL, Liu T (2015). Preventive effects of phenylethanol glycosides from Cistanche tubulosa on bovine serum albumin-induced hepatic fibrosis in rats. Daru, 23: 52

[89] You SP, Ma L, Zhao J, Zhang SL, Liu T (2016). Phenylethanol glycosides from Cistanche tubulosa suppress hepatic stellate cell activation and block the conduction of signaling pathways in TGFbeta1/smad as potential anti-hepatic fibrosis agents. Molecules, 21: 102

[90] Dai LH, Shen YM, Wu YH, Yu XP, Hu HJ, Mi YJ, et al. (2015). Effect of echinacoside on replication and antigen expression of hepatitis $\mathrm{B}$ virus. Zhongguo Zhong Yao Za Zhi, 40: 3047-3052

[91] Nakamura T, Matsumoto T, Sugimoto T, Shiraki M (2012). Dose-response study of denosumab on bone mineral density and bone turnover markers in Japanese postmenopausal women with osteoporosis. Osteoporos Int, 23: 1131-1140

[92] Wang X, Zhen L, Zhang G, Wong MS, Qin L, Yao X (2011). Osteogenic effects of flavonoid aglycones from an osteoprotective fraction of Drynaria fortunei-an in vitro efficacy study. Phytomedicine, 18: 868872

[93] Li F, Yang Y, Zhu P, Chen W, Qi D, Shi X, et al. (2012). Echinacoside promotes bone regeneration by increasing OPG/RANKL ratio in MC3T3-E1 cells.
Fitoterapia, 83: 1443-1450

[94] Li F, Yang X, Yang Y, Guo C, Zhang C, Yang Z, et al. (2013). Antiosteoporotic activity of echinacoside in ovariectomized rats. Phytomedicine, 20: 549-557

[95] Yang X, Li F, Yang Y, Shen J, Zou R, Zhu P, et al. (2013). Efficacy and safety of echinacoside in a rat osteopenia model. Evid Based Complement Alternat Med, 2013: 926928

[96] Tian Y, Di Y, Bao CF, Lin YH, Qin SJ (2015). Effect of echinacoside-containing serum in promoting mesenchymal stem cell osteogenic differentiation and ZHX(3) expression in rats. Zhongguo Zhong Yao Za Zhi, 40: 4052-4057

[97] Kim SW, Yoo SH, Lee HJ, Kim K, Kim DR, Park SK, et al. (2012). Cistanches herba induces testis cytotoxicity in male mice. Bull Environ Contam Toxicol, 88: 112-117

[98] Jiang Z, Wang J, Li X, Zhang X (2016). Echinacoside and Cistanche tubulosa (Schenk) R. wight ameliorate bisphenol A-induced testicular and sperm damage in rats through gonad axis regulated steroidogenic enzymes. J Ethnopharmacol, 193: 321-328

[99] Xiong WT, Gu L, Wang C, Sun HX, Liu X (2013). Anti-hyperglycemic and hypolipidemic effects of Cistanche tubulosa in type 2 diabetic $\mathrm{db} / \mathrm{db}$ mice. J Ethnopharmacol, 150: 935-945

[100] Morikawa T, Ninomiya K, Imamura M, Akaki J, Fujikura S, Pan Y, et al. (2014). Acylated phenylethanoid glycosides, echinacoside and acteoside from Cistanche tubulosa, improve glucose tolerance in mice. J Nat Med, 68: 561-566

[101] Xiong Q, Hase K, Tezuka Y, Namba T, Kadota S (1999). Acteoside inhibits apoptosis in Dgalactosamine and lipopolysaccharide-induced liver injury. Life Sci, 65: 421-430

[102] Zhao J, Liu T, Ma L, Yan M, Zhao Y, Gu Z, et al. (2009). Protective effect of acteoside on immunological liver injury induced by Bacillus Calmette-Guerin plus lipopolysaccharide. Planta Med, 75: 1463-1469

[103] Lin J, Gao L, Huo SX, Peng XM, Wu PP, Cai LM, et al. (2012). Effect of acteoside on learning and memory impairment induced by scopolamine in mice. Zhongguo Zhong Yao Za Zhi, 37: 2956-2959

[104] Peng XM, Gao L, Huo SX, Liu XM, Yan M (2015). The mechanism of memory enhancement of acteoside (verbascoside) in the senescent mouse model induced by a combination of D-gal and $\mathrm{AlCl} 3$. Phytother Res, 29: 1137-1144

[105] Gao L, Peng XM, Huo SX, Liu XM, Yan M (2015). Memory enhancement of acteoside (verbascoside) in a senescent mice model induced by a combination of D-gal and AlCl3. Phytother Res, 29: 1131-1136

[106] Chiou WF, Lin LC, Chen CF (2004). Acteoside protects endothelial cells against free radical-induced oxidative stress. J Pharm Pharmacol, 56: 743-748

[107] Wang P, Zheng R, Gao J, Jia Z, Wang W, Yao S, et al. (1996). Reaction of hydroxyl radical with phenylpropanoid glycosides from Pedicularis species: a pulse radiolysis study. Sci China C Life Sci, 39: 


\section{$154-158$}

[108] Yuan J, Ren J, Wang Y, He X, Zhao Y (2016). Acteoside binds to caspase-3 and exerts neuroprotection in the rotenone rat model of Parkinson's disease. PLoS One, 11: e0162696

[109] Bai P, Peng XM, Gao L, Huo SX, Zhao PP, Yan M (2013). Study on protective effect of acteoside on cellular model of Alzheimer's disease induced by okadaic acid. Zhongguo Zhong Yao Za Zhi, 38: 1323-1326

[110] Yamada P, Iijima R, Han J, Shigemori H, Yokota S, Isoda $\mathrm{H}$ (2010). Inhibitory effect of acteoside isolated from Cistanche tubulosa on chemical mediator release and inflammatory cytokine production by RBL-2H3 and KU812 cells. Planta Med, 76: 15121518

[111] Motojima H, Villareal MO, Iijima R, Han J, Isoda H (2013). Acteoside inhibits type Iota allergy through the down-regulation of $\mathrm{Ca} / \mathrm{NFAT}$ and JNK MAPK signaling pathways in basophilic cells. J Nat Med, 67: 790-798

[112] Yang JH, Hu JP, Rena K, Du NS (2009). Structureactivity relationships of phenylethanoid glycosides in plants of Cistanche salsa on antioxidative activity. Zhong Yao Cai, 32: 1067-1069

[113] Zheng QL, Zheng YF, Lu ZL (2002). Immunomodulatory effects of polysaccharide of Cistanche Deserticola Y C Ma. Zhejiang Da Xue Xue Bao Yi Xue Ban, 31: 284-287

[114] Wu XM, Gao XM, Tsim KW, Tu PF (2005). An arabinogalactan isolated from the stems of Cistanche deserticola induces the proliferation of cultured lymphocytes. Int J Biol Macromol, 37: 278-282

[115] Zhang W, Huang J, Wang W, Li Q, Chen Y, Feng W, et al. (2016). Extraction, purification, characterization and antioxidant activities of polysaccharides from Cistanche tubulosa. Int J Biol Macromol, 93: 448-458

[116] Guo Y, Cao L, Zhao Q, Zhang L, Chen J, Liu B, et al. (2016). Preliminary characterizations, antioxidant and hepatoprotective activity of polysaccharide from Cistanche deserticola. Int J Biol Macromol, 93: 678685

[117] Dong Q, Yao J, Fang JN, Ding K (2007). Structural characterization and immunological activity of two cold-water extractable polysaccharides from Cistanche deserticola Y. C. Ma. Carbohydr Res, 342: 1343-1349

[118] Yamaguchi K, Shinohara C, Kojima S, Sodeoka M, Tsuji T (1999). (2E,6R)-8-hydroxy-2,6-dimethyl-2octenoic acid, a novel anti-osteoporotic monoterpene, isolated from Cistanche salsa. Biosci Biotechnol Biochem, 63: 731-735

[119] Jeon HJ, Chung KS, An HJ (2016). Anti-proliferation effects of Cistanches salsa on the progression of benign prostatic hyperplasia. Can J Physiol Pharmacol, 94: 104-111

[120] Tian XF, Pu XP (2005). Phenylethanoid glycosides from Cistanches salsa inhibit apoptosis induced by 1 methyl-4-phenylpyridinium ion in neurons. $\mathrm{J}$
Ethnopharmacol, 97: 59-63

[121] Geng X, Song L, Pu X, Tu P (2004). Neuroprotective effects of phenylethanoid glycosides from Cistanches salsa against 1-methyl-4-phenyl-1,2,3,6tetrahydropyridine (MPTP)-induced dopaminergic toxicity in C57 mice. Biol Pharm Bull, 27: 797-801

[122] Xie H, Zhu H, Cheng C, Liang Y, Wang Z (2009). Echinacoside retards cellular senescence of human fibroblastic cells MRC-5. Pharmazie, 64: 752-754

[123] Zhang J, Zhang Z, Xiang J, Cai M, Yu Z, Li X, et al. (2017). Neuroprotective effects of echinacoside on regulating the stress-active p38MAPK and NFkappaB p52 signals in the mice model of Parkinson's disease. Neurochem Res, in press

[124] Deng M, Zhao JY, Tu PF, Jiang Y, Li ZB, Wang YH (2004). Echinacoside rescues the SHSY5Y neuronal cells from TNFalpha-induced apoptosis. Eur J Pharmacol, 505: 11-18

[125] He W, Fang T, Tu P (2009). Research progress on pharmacological activities of echinacoside. Zhongguo Zhong Yao Za Zhi, 34: 476-479

[126] Li X, Gou C, Yang H, Qiu J, Gu T, Wen T (2014). Echinacoside ameliorates D-galactosamine plus lipopolysaccharide-induced acute liver injury in mice via inhibition of apoptosis and inflammation. Scand J Gastroenterol, 49: 993-1000

[127] Geng X, Tian X, Tu P, Pu X (2007). Neuroprotective effects of echinacoside in the mouse MPTP model of Parkinson's disease. Eur J Pharmacol, 564: 66-74

[128] Wang YH, Xuan ZH, Tian S, Du GH (2015). Echinacoside Protects against 6-HydroxydopamineInduced Mitochondrial Dysfunction and Inflammatory Responses in PC12 Cells via Reducing ROS Production. Evid Based Complement Alternat Med, 2015: 189239

[129] Zhao Q, Yang X, Cai D, Ye L, Hou Y, Zhang L, et al. (2016). Echinacoside protects against $\mathrm{MPP}(+)$ induced neuronal apoptosis via ROS/ATF3/CHOP pathway regulation. Neurosci Bull, 32: 349-362

[130] Chen H, Jing FC, Li CL, Tu PF, Zheng QS, Wang ZH (2007). Echinacoside prevents the striatal extracellular levels of monoamine neurotransmitters from diminution in 6-hydroxydopamine lesion rats. $\mathbf{J}$ Ethnopharmacol, 114: 285-289

[131] Wu Y, Li L, Wen T, Li YQ (2007). Protective effects of echinacoside on carbon tetrachloride-induced hepatotoxicity in rats. Toxicology, 232: 50-56

[132] Mulani SK, Guh JH, Mong KK (2014). A general synthetic strategy and the anti-proliferation properties on prostate cancer cell lines for natural phenylethanoid glycosides. Org Biomol Chem, 12: 2926-2937

[133] Wang W, Luo J, Liang Y, Li X (2016). Echinacoside suppresses pancreatic adenocarcinoma cell growth by inducing apoptosis via the mitogen-activated protein kinase pathway. Mol Med Rep, 13: 26132618

[134] Pu X, Song Z, Li Y, Tu P, Li H (2003). Acteoside from Cistanche salsa inhibits apoptosis by 1-methyl4-phenylpyridinium ion in cerebellar granule neurons. 
Planta Med, 69: 65-66

[135] Yang J, Yan Y, Liu H, Wang J, Hu J (2015). Protective effects of acteoside against $\mathrm{X}$-ray-induced damage in human skin fibroblasts. Mol Med Rep, 12: 2301-2306

[136] Sheng G, Pu X, Lei L, Tu P, Li C (2002). Tubuloside $\mathrm{B}$ from Cistanche salsa rescues the PC12 neuronal cells from 1-methyl-4-phenylpyridinium ion-induced apoptosis and oxidative stress. Planta Med, 68: 966970
[137]

Deng M, Zhao JY, Ju XD, Tu PF, Jiang Y, Li ZB (2004). Protective effect of tubuloside $B$ on TNFalpha-induced apoptosis in neuronal cells. Acta Pharmacol Sin, 25: 1276-1284

[138] Bougandoura A, D'Abrosca B, Ameddah S, Scognamiglio M, Mekkiou R, Fiorentino A, et al. (2016). Chemical constituents and in vitro antiinflammatory activity of Cistanche violacea Desf. (Orobanchaceae) extract. Fitoterapia, 109: 248-253 